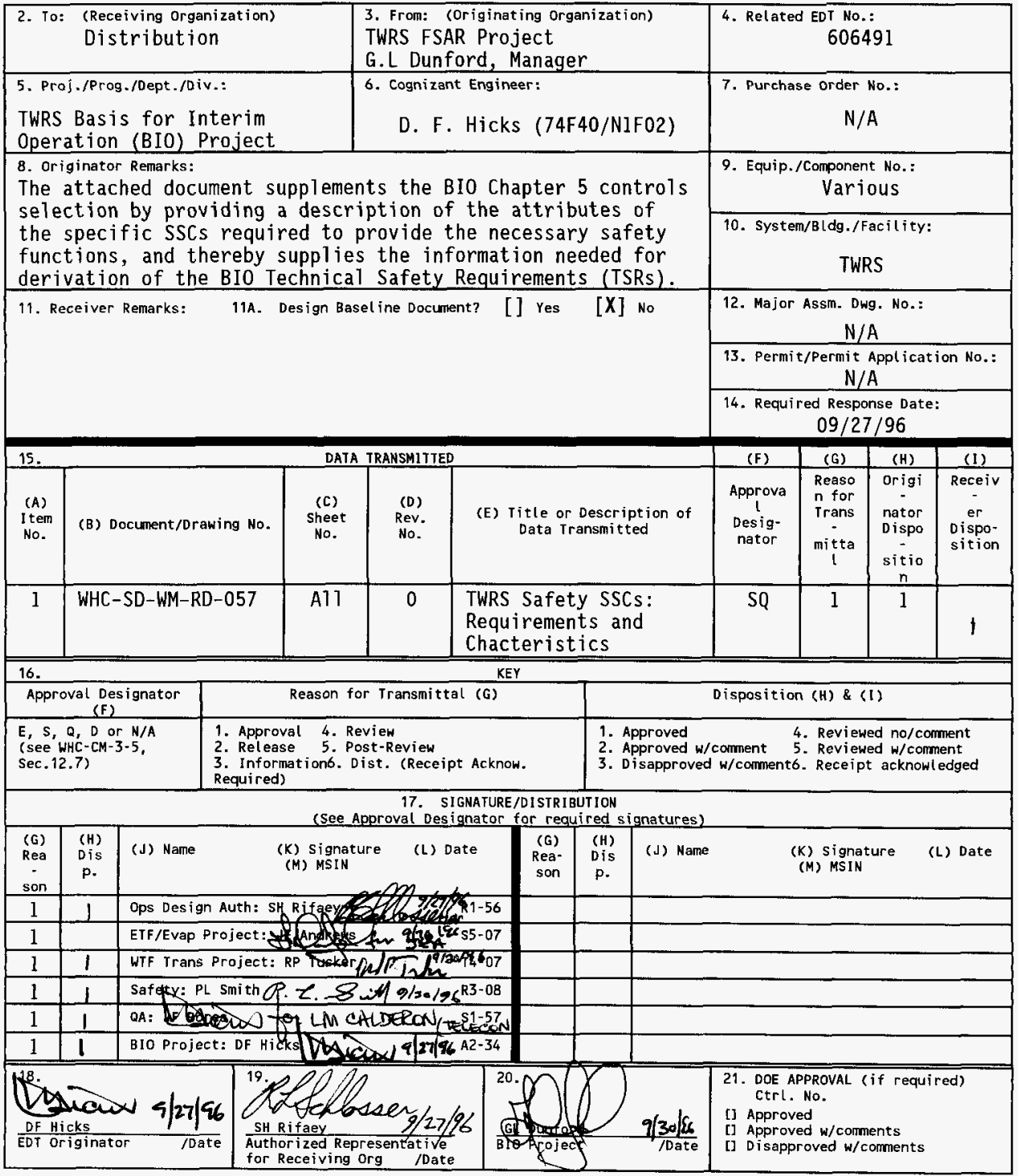

BD-7400-172-2 (05/96) GEF097 


\section{Tank Waste Remediation System Safety Structures, Systems, and Components: Requirements and Characteristics}

D F HICKS

WHC, Richland, WA 99352

U.S. Department of Energy Contract DE-AC06-87RL10930

$\begin{array}{llll}\text { EDT /ECN: } & 613528 & \text { UC: } & 2030 \\ \text { Org Code: } & 74 F 40 & \text { Charge Code: } & \text { N1F02 } \\ \text { B\&R Code: } & \text { EW3120071 } & \text { Total Pages: } & 63\end{array}$

Key Words: Basis for Interim Operations; Tank Farms; TWRS; Single-Shell Tanks; Double-Shell Tanks; Aging Waste Facility; Safety Analysis; Systems, Structures, and Components

Abstract: Safety Systems, Structures, and Components (SSCs) have been identified from hazard and accident analyses. These analyses were performed to support the Tank Waste Remediation System (TWRS) Final Safety Analysis Report (FSAR) and Basis for Interim Operation (BIO). The text identifies and evaluates the SSCs, and their supporting SSC's, to show that they either prevent the occurrence of the accident or, mitigate the consequences of the accident to below the acceptance guidelines. The requirements for the SSC's to fulfill these tasks are described.

TRADEMARK DISCLAIMER. Reference herein to any specific commercial product, process, or service by trade name, trademark, manufacturer, or otherwise, does not necessarily constitute or imoly its endorsement, recommendation, or favoring by the United States Goverment or any agency thereof or its contractors or subcontractors.

Printed in the United States of America. To obtain copies of this document, contact: WHC/BCS Document Control Services, P.0. Box 1970, Mail-stop H6-08, Richland HA 99352, Phone (509) 372-2420; Fax (509) 376-4989.
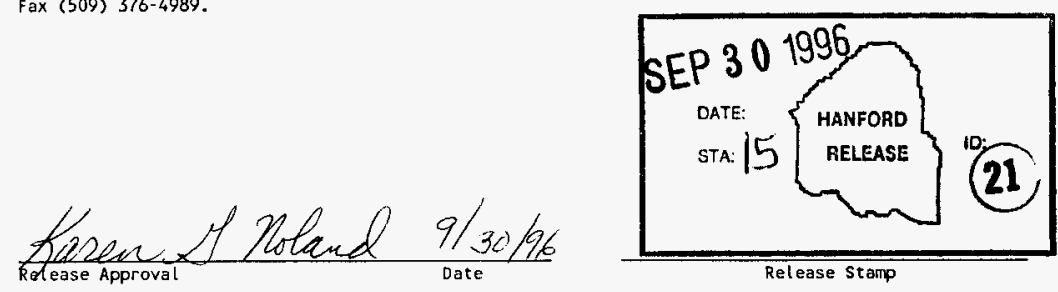

Approved for Public Release 


\title{
Tank Waste Remediation System Safety Structures, Systems, and Components: Requirements and Characteristics (U)
}

\author{
D. F. Hicks \\ M. A. Smith-Fewell \\ M. D. VanderZanden \\ S. White \\ Westinghouse Hanford Company \\ C. Zaccone \\ Stone \& Webster Engineering Corporation \\ R. E. Hardwick \\ $H$ \& R Technical Associates, Inc.
}

September, 1996

Westinghouse Hanford Company

Richland, Washington 99352 
WHC-SD-WM-RD-057, Rev. 0

This page intentionally left blank. 
WHC-SD-WM-RD-057, Rev. 0

TABLE OF CONTENTS

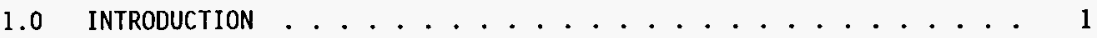

2.0 SAFETY SYSTEMS, STRUCTURES, AND COMPONENTS ........ 3

2.1 NUCLEAR CRITICALITY $(01) \ldots \ldots$

2.2 HEPA FILTER FAILURE - EXPOSURE TO HIGH TEMPERATURE OR

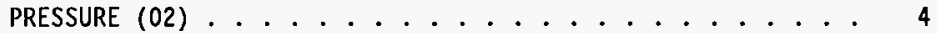

2.2.1 Ventilation CAM Interlock Systems ........ 4

2.3 FIRE IN CONTAMINATED AREA (03) ........... 5

2.4 EVAPORATOR DUMP $(04) \ldots \ldots$

2.5 STEAM INTRUSION FROM INTERFACING SYSTEMS $(05) \ldots \ldots \ldots$

2.6 LEAK FROM RAIL CAR OR TANK TRAILER $(06) \ldots \ldots$

2.7 SUBSURFACE LEAK REMAINING SUBSURFACE $(07) \ldots \ldots \ldots$

2.7.1 Transfer Leak Detection Systems . . . . . . . . 6

2.7 .2 Pipe Encasements . . . . . . . . . . . 7

2.7.3 Tank Level Detection Systems ........... 7

2.7 .4 Salt Well Flow Totalizers ......... 8

2.8 UNPLANNED EXCAVATION/DRILLING IN POND/CRIB/DITCH (O8) ... 9

2.9 CAUSTIC SPRAY LEAK $(09) \ldots \ldots \ldots$

2.10 SODIUM FIRE $(10) \ldots \ldots . . \ldots . . \ldots 9$

2.10 .12727 W Building ............. . . 9

2.11 MIXING OF INCOMPATIBLE MATERIAL - TOXIC VAPOR GENERATION

(11) . . . . . . . . . 10

2.12 MIXING OF INCOMPATIBLE MATERIAL - TANK PRESSURIZATION (12) : 10

2.12.1 HEPA Filters (One stage required on 244-S, 244-TX,
and 244-A) 10

2.13 TANK FAILURE DUE TO EXCESSIVE LOADS $(13) \ldots \ldots \ldots$

2.14 FLAMMABLE GAS DEFLAGRATIONS $(14) \ldots \ldots \ldots$

2.14.1 DST/AWF Ventilation ............ 10

2.14.2 Primary Tank Leak Detection Systems . . . . . . 12

2.14 .3 SST Ventilation ............. 13

2.14.4 DCRT Level Dip Tube Flow ........... 14

2.14.5 TK-002 244-AR Leve1 Dip Tube Flow. . . . . . . 15

2.14.6 SY-101 Mixer Pump . . . . . . . . . . . . . 16

2.14 .7 SY-101 Hydrogen Monitor . . . . . . . . . 17

2.14.8 SY-101 Level Monitoring System . . . . . . . . 18

2.14.9 SY-101 Pressure Monitoring System . . . . . . . . 19

2.14.10 SY-101 Ventilation Flowmeter........... 19

2.14 .11 SY-101 Ammonia Detection Systems . . . . . 20

2.14 .12 SY-101 Temperature Monitoring System . . . . . . 21

2.15 ORGANIC SOLVENT FIRE $(15) \ldots \ldots \ldots \ldots . \ldots . \ldots . \ldots 22$

2.16 IN-TANK FUEL FIRE/DEFLAGRATION (16) . . . . . . . . 22

2.17 ORGANIC SALT - NITRATE REACTION (17) .......... 22

2.18 SURFACE LEAK RESULTING IN POOL (18) .................. 22

2.18 .1 Transfer Leak Detection Systems . . . . . . . 22

2.18 .2 Primary Tank Leak Detection Systems . . . . . 23

2.18.3 Pressure Switch Interlocks or Alarms (Water Service

Lines) ................... 24

2.18 .4 OGT Encasement and Connections . . . . . 25

2.18 .5 OGT Concrete Shielding System . . . . . . 26

2.18 .6 Tank Level Detection Systems ................ 27

2.18 .7 Salt Well Flow Totalizers . . . . . . . 28

2.18 .8 Transfer System Covers . . . . . . . . 28 
2.18.9 Service Water Flow Totalizers .......... . 29

2.19 SUBSURFACE LEAK RESULTING IN POOL (19) . . . . . . . . . . 30

2.19.1 Pipe Encasements ................ . 30

2.19.2 Tank Level Detection Systems . . . . . . . . . . 31

2.19 .3 Salt Well Flow Totalizers . . . . . . . . . . 32

2.20 SPRAY LEAK IN STRUCTURE OR FROM OVERGROUND WASTE TRANSFER

LINES (20) . . . . . . . . . . . . . . . . 32

2.20.1 Transfer System Covers . . . . . . . . . . . 32

2.20.2 Pressure Switch Interlocks or Alarms (Water Service Lines) ............... . . 33

2.20.3 Ventilation CAM Interlock Systems . . . . . . . 34

2.20.4 OGT Encasement and Connections . . . . . . . . 35

2.20.5 OGT Concrete Shielding System . . . . . . . . . 36

2.20 .6 204-AR Building ................ . 37

2.20.7 Backflow Prevention Devices........ . . . . 38

2.21 SPRAY LEAK FROM UNDERGROUND WASTE TRANSFER LINES (21) . . . . 38

2.22 TANK BUMP (22) ..................... 38

2.22.1 Temperature Monitoring Systems . . . . . . . . 39

2.22.2 Tank Level Detection Systems . . . . . . . . . . 39

2.23 NATURAL PHENOMENA (23) . . . . . . . . . . . . . 40

3.0 REFERENCES ......................... 41

\section{APPENDIX}

A. Accident/SSC Cross-Reference Table . . . . . . . . . . . . . . . . 43

B. Safety-Class/Safety-Significant Transfer System Covers . . . . . . . 47 


\section{LIST OF TERMS}

$\begin{array}{ll}\text { AWF } & \text { aging waste facility } \\ \text { B \& K } & \text { Breurl \& Kjaer (ammonia detector) } \\ \text { BIO } & \text { Basis for Interim Operation } \\ \text { CAM } & \text { continuous air monitor } \\ \text { CASS } & \text { Computer Automated Surveillance System } \\ \text { DACS } & \text { Data Acquisition Control System } \\ \text { DCRT } & \text { double-contained receiver tank } \\ \text { DOE } & \text { U.S. Department of Energy } \\ \text { DST } & \text { double-shell tank } \\ \text { FIC } & \text { Food Instrument Corporation (level instrument) } \\ \text { FIT } & \text { flow indicator transmitter } \\ \text { FSAR } & \text { Final Safety Analysis Report } \\ \text { FTIR } & \text { Fourier Transfer Infra-Red (spectrometer) } \\ \text { GRE } & \text { gas release event } \\ \text { HEPA } & \text { high-efficiency particulate air (filter) } \\ \text { LFL } & \text { lower flammability limit } \\ \text { MIT } & \text { multi-instrument tree } \\ \text { NC } & \text { non-convecting } \\ \text { OGT } & \text { overground transfer } \\ \text { SHMS } & \text { Standard Hydrogen Monitoring System } \\ \text { SSC } & \text { structure, system, or component } \\ \text { SST } & \text { single-shell tank } \\ \text { TMACS } & \text { Tank Monitoring and Control System } \\ \text { TSR } & \text { Technical Safety Requirement } \\ \text { TWRS } & \text { Tank Waste Remediation System } \\ \text { WHC } & \text { Westinghouse Hanford Company } \\ \end{array}$


WHC-SD-WM-RD-057, Rev. 0

This page intentionally left blank. 
WHC-SD-WM-RD-057, Rev. 0

\section{TANK WASTE REMEDIATION SYSTEM SAFETY STRUCTURES, SYSTEMS, AND COMPONENTS: REQUIRENENTS AND CHARACTERISTICS}

\subsection{INTRODUCTION}

In anticipation of the Tank Waste Remediation System (TWRS) Final Safety Analysis Report (FSAR), the TWRS Basis for Interim Operation (BIO), WHC-SD-WMBI0-001, has been prepared. To support the BIO, this supporting document (SD) was developed to provide interim requirements for the safety structures, systems and components (SSCS) and to define the essential characteristics that they need to provide their safety functions. Chapter 5 of the BIO, "Safety Analyses", documents the selection of controls for 23 accident scenarios, and supports the selection with confirming analyses. The selected controls will maintain the facility within a safe operating envelope and protect the facility worker, the onsite worker, the offsite public, and the environment. The safety analyses process of identifying safety SSCs involved a graded approach for applying design and quality requirements to engineered features that maintain or perform safety functions. Selection of controls was done by an experienced team which included operations, hazard analysis, accident analysis, management, engineering, and appropriate subject matter specialists. This document supplements the Chapter 5 controls selection by providing a description of the attributes of the specific SSCs required to provide the necessary safety functions, and thereby supplies the information needed for derivation of the Technical Safety Requirements (TSRs) for the BIO.

The SSCs included in this document are divided into two categories, safety-class SSCS and safety-significant SSCS. Safety-class SSCs prevent or mitigate releases to the public that would otherwise exceed the offsite radiological risk guidelines, or prevent a nuclear criticality. Those SSCs that support the safety function of a safety-class SSC are also safety-class SSCs.

Safety-significant SSCS prevent or mitigate releases of radiological materials to onsite workers and toxic chemicals to the offsite public and onsite workers. Safety-significant also describes worker safety SSCs that protect the facility worker from serious injury (or fatality) due to hazards not controlled by institutional safety programs. Those SSCS which support the safety function of a safety-significant SSC are also safety-significant.

Chapter 5 of the BIO identifies the safety SSCs required to either reduce the risk or mitigate consequences of each accident. This document provides a summary description and an evaluation of the attributes and critical characteristics of each safety SSC identified in Chapter 5 of the BIO. For example, in the BIO, five safety-class SSCs and two safetysignificant SSCs are identified for the accident scenario for "Spray Leak in Structure or From Overground Transfer Lines". In this document, each of the seven safety SSCs for this accident scenario is described separately, using a format which identifies the functional requirements and critical characteristics of the safety SSC. Depending on the safety function, a safety-class SSC for one accident scenario could also be a safety-significant SSC for another accident scenario. Appendix $A$ of this document provides a 
cross-reference, listing each safety SSC and its safety classification relative to each accident for which it performs a safety function.

The following structures are not included in the 1ist of safety-class or safety-significant SSCs in this supporting document. The classification of these passive design features as safety-class, safety-significant, or general services will be provided in the TWRS FSAR.

Double-she11 tanks (DSTs)

Aging Waste Facility (AWF) tanks

Single-shell tanks (SSTs)

Double-contained receiver tanks (DCRTs)

Catch tanks

Process pits

Diversion boxes

Vault pits

Cleanout boxes

Transfer lines 
WHC-SD-WM-RD-057, Rev. 0

\subsection{SAFETY SYSTEMS, STRUCTURES, AND COMPONENTS}

This section lists each accident described in Chapter 5 of the BI0 by name and tracking number, followed by a list of the safety-class and safetysignificant SSCs identified for that accident. The following information is provided for each safety SSC.

\section{SSC Name:}

The SSC identification is established. An SSC may be listed under more than one accident. For example, the Salt Well Flow Totalizers are identified as a safety SSC for the Subsurface Leak Remaining Subsurface accident, the Surface Leak Resulting in Pool accident, and the Subsurface Leak Resulting in Pool accident. The Salt Well Flow Totalizers are listed and described separately for each of those accidents.

\section{Safety Classification:}

The safety classification indicates whether the SSC is a safetyclass or safety-significant SSC for its role in preventing or mitigating the particular accident. An SSC may be identified as a safety-class SSC for one accident, and as a safety-significant SSC for another accident.

\section{Safety Function:}

The safety function statement is drawn directly from the accident analysis, and defines the role of the SSC in preventing or mitigating the consequences of the accident. The safety function is a statement of the reason for identifying a safety SSC as safety-class or safety-significant.

\section{System Description:}

This section gives a brief description of the SSC and the basic principles by which it performs its safety function. The boundaries and interface points of the safety SSC with other SSCS relevant to the safety function are also presented.

\section{Functional Requirements:}

The functional requirements are those that are specifically needed to fulfill the identified safety functions for the specific accident(s) where the safety SSC must function. If a safety SSC were required to function at an elevated temperature to perform its safety function, qualification of the SSC for operation in that temperature range would be a functional requirement. A more detailed evaluation of nonambient environmental factors for safety SSCS will be developed in the FSAR.

\section{System Evaluation:}

The system evaluation provides performance criteria imposed on the SSC in order to ensure the SSC can meet its functional requirements and thereby satisfy its safety function. Performance criteria characterize the specific operational responses and capabilities necessary to meet functional requirements, and an evaluation of the capabilities of the safety SSC to meet performance criteria is made where possible. A more detailed 
WHC-SD-WM-RD-057, Rev. 0

evaluation will be provided in Chapter 4 of the FSAR. The manner of verification for these performance criteria is specified, and may include required calibration, challenge tests, or other functional test procedures. Engineering judgement may be used to develop performance criteria for existing safety SSCs (i.e., those safety SSCs which are already designed, installed and operating in the field). Existing criteria traditionally associated with safety SSCs, such as single failure criteria, may be considered in the judgement process; however, for safety SSCs that already exist, formal design comparison and compliance with traditional safety SSC performance criteria is not required.

\section{Supporting SSCs:}

Supporting SSCs are those SSCs whose failure would result in the identified safety SSC losing the ability to perform its safety function. Some typical supporting SSCS are electrical power and instrument air.

This report has been developed to support preparation of the TWRS BIO. The attributes of the SSCS, which include the safety functions, functional requirements and system evaluations, will be used for development of the TSRs. The descriptions of the safety-class and safety-significant SSCs and identification of their critical attributes complement the controls summaries of Chapter 5 of the BIO, and support the final conclusion in the BIO that the TWRS facility can be operated safely.

\subsection{NUCLEAR CRITICALITY (01)} accident.

No safety-class or safety-significant SSCs were identified for this

\subsection{HEPA FILTER FAILURE - EXPOSURE TO HIGH TEMPERATURE OR PRESSURE (02)}

\subsubsection{Ventilation CAM Interlock Systems}

2.2.1.1 Safety Classification. The Ventilation Continuous Air Monitor (CAM) Interlock Systems are identified as safety-significant SSCs for the HEPA Filter Failure - Exposure to High Temperature or Pressure accident.

2.2.1.2 Safety Function(s). Prevent the unfiltered release from occurring for more than 10 minutes.

2.2.1.3 System Description. The CAMs and interlocks on the ventilation exhaust stacks for a 11 DSTs, AWF tanks, and actively ventilated SSTs are required to perform the above safety function. The following is a list of those stacks.

296-A-17

296-A-27

$296-\mathrm{A}-29$

296-A-40

296-P-16
241-AY/AZ Tank Farms Exhauster

241-AW Tank Farm Exhauster

241-AN Tank Farm Exhauster

241-AP Tank Farm Exhauster

241-C-105/106 Tank Exhauster 
WHC-SD-WM-RD-057, Rev. 0

\author{
296-P-23 241-SY Tank Farm Backup Exhauster (K1-4-1) \\ 296-P-26 241-AY/AZ Tank Farms Backup Exhauster (4,000 cfm portable \\ exhauster) \\ 296-P-28 241-SY Tank Farm (Second) Backup Exhauster \\ 296-S-15 241-SX Tank Farm Exhauster \\ 296-S-25 241-SY New Tank Exhauster
}

Typically, a vacuum pump pulls a gaseous effluent sample from the exhaust stack through a sample line into the CAM, and discharges the sample either back to the stack or through a filter to the atmosphere. Isokinetic sampling conditions are maintained by automatic or manual adjustment of the flow rate. If the CAM detects high radiation in the exhaust stream, an alarm is actuated, and a signal is transmitted to a relay which interrupts the electrical power to the exhaust fan motor, causing the fan to stop operating.

Tank farms 241-AN, 241-AP, and 241-AW have backup exhaust systems that start automatically after the CAM interlock shuts down the primary exhaust fan. The backup systems are not equipped with CAM high radiation interlocks, and will continue operating after a HEPA filter failure. Interlocks must be installed on the backup systems in order for the systems to perform the above safety function.

The CAMs have not generally performed satisfactorily, with mean time between failures measured in months. The electrical interlock deenergizing the exhaust fan is considered reliable. CAMs are vulnerable to loss of sample flow; low sample flow rate and other CAM malfunctions are normally detected and al armed.

2.2.1.4 Functional Requirements. The CAM must operate continuously while the exhaust systems are operating, maintaining isokinetic sampling conditions. The CAM must measure the radiation level in the sampled flow stream and detect levels in excess of a preset level. The CAM shall activate an interlock to shut down the exhauster within 10 minutes of detecting a radiation level that exceeds the preset level. Upon CAM failure, the monitors must actuate an al arm and/or an interlock to shut down the exhaust system.

2.2.1.5 System Evaluation. The CAMs shall be calibrated annually, and the alarms and interlocks shall be functionally tested once a month. The CAMs shall be source checked weekly to verify appropriate system response.

2.2.1.6 Supporting SSCs. Electrical power for the CAM, for the interlock and alarm, for the cabinet heaters and fans, and for freeze protection heaters for the gas tubing.

\title{
2.3 FIRE IN CONTAMINATED AREA (03)
} accident.

No safety-class or safety-significant SSCs were identified for this

\subsection{EVAPORATOR DUMP (04)} accident.

No safety-class or safety-significant SSCs were identified for this 
WHC-SD-WM-RD-057, Rev. 0

\subsection{STEAM INTRUSION FROM INTERFACING SYSTEMS (05)} accident.

No safety-class or safety-significant SSCs were identified for this

\subsection{LEAK FROM RAIL CAR OR TANK TRAILER (06)} accident.

No safety-class or safety-significant SSCs were identified for this

\subsection{SUBSURFACE LEAK REMAINING SUBSURFACE (07)}

\subsubsection{Transfer Leak Detection Systems}

2.7.1.1 Safety Classification. The Transfer Leak Detection Systems (pit leak detectors) are identified as safety-significant SSCs for the Subsurface Leak Remaining Subsurface accident.

2.7.1.2 Safety Function(s). Detect leaks (1) in waste transfer piping systems located within transfer-associated structures and (2) in primary pipe of encased waste transfer lines that drain to transfer-associated structures.

2.7.1.3 System Description. Pit leak detectors have electrodes at different electrical potentials which are short circuited by a conductive medium (i.e., liquid waste) and cause a change in state of the monitoring circuitry. Pit leak detectors are located one inch above the floor in the lowest part of the pit or in a sump in the pit. When liquid waste short circuits the pit leak detector electrodes, an alarm is generated. The wiring between the leak detector and the control panel is electrically supervised. The alarm function associated with the leak detector is testable.

Conductivity probes have performed reliably as transfer pit leak detectors for many years, with mean time between failures measured in years.

2.7.1.4 Functional Requirements. Pit leak detectors shall detect a 1 inch deep pool of liquid waste in the bottom of the pit, and shall provide an alarm when such a pool is detected.

2.7.1.5 System Evaluation. The operation of each pit leak detector and its associated alarm(s) shall be verified prior to each transfer of waste through a route connected with the pit, and at least annually. The alarm feature annunciation shall be verified prior to each waste transfer through a route connected with the pit. The pit leak detection alarm circuitry shall be tested periodically to verify that a loss of alarm circuit continuity will result in an alarm.

\subsubsection{Supporting SSCs. Electrical power for alarm circuitry.}


WHC-SD-WM-RD-057, Rev, 0

\subsubsection{Pipe Encasements}

2.7.2.1 Safety Classification. The Pipe Encasements for the waste transfer system are identified as safety-significant SSCs for the Subsurface Leak Remaining Subsurface accident.

2.7.2.2 Safety Function(s). Prevent the release of waste to the soil from a primary transfer pipe leak.

2.7.2.3 System Description. Waste transfer system piping is encased by one of two methods:

- It is fabricated as pipe within a pipe, with an inner or primary pipe surrounded by an encasement or secondary pipe. The encasement pipe forms a sloped annular drain channel, and any leaked waste from a primary pipe will gravity flow from the leak site along this annular channe1.

- The primary pipe(s) are confined in a concrete encasement. The concrete encasement forms a sloped drain channel, and any leaked waste from a primary pipe will gravity flow from the leak site along this channel.

Regardless of the encasement form, leaked waste will be channeled through the loop seals (with valves fully open), and into a transferassociated structure along the transfer route, where the transfer leak detection system (described in Section 2.7.1) will detect the leaked waste.

Pipe encasements are vulnerable to damage during excavation activities in Tank Farms, particularly when powered equipment is used for digging.

2.7.2.4 Functional Requirements. The pipe encasement shall route waste leaked from the primary pipe to a structure where the leak can be detected. (The leak detection system is described in Section 2.7.1 of this document.) The encasement shall provide an unobstructed flow path to the structure.

2.7.2.5 System Evaluation. The drain path into the pit(s) from the annulus of the encased piping system shall be verified to be free of obstructions (i.e., the loop seal valves shall be in their fully open position) prior to the start of a waste transfer.

\subsubsection{Supporting SSCs. None.}

\subsubsection{Tank Level Detection Systems}

2.7.3.1 Safety Classification. The Tank Level Detection Systems are identified as safety-significant SSCs for the Subsurface Leak Remaining Subsurface accident.

2.7.3.2 Safety Function(s). Provide tank waste level in sending/receiving tank to aid in detecting leaks.

2.7.3.3 System Description. Each DST (including AWF tanks), SST, DCRT, and catch tank is equipped with a surface level detection system. Each system includes at least one level detector, which may be a manual tape, an FIC, an ENRAF gauge, or a set of dip tubes. Each DST has either an FIC or an ENRAF 
gauge and a manual tape backup; most SSTs, DCRTs, and catch tanks have a single level detector. Level data can be locally read, and are automatically or manually provided to TMACS and/or CASS. The 241-SY-101 level detection system contains both an FIC and an ENRAF gauge, and provides data to the Data Acquisition Control System (DACS) as well as to TMACS. Level increases and decreases are detected by comparison of current level measurements with previous measurements. Data from the level detection systems of the sending tank, the receiving tank, and tanks interconnected with the transfer routes are recorded at specified intervals during a waste transfer, for use in detecting a potential leak or misrouting.

Five types of tank level detection systems are employed in Tank Farms. $A$ dissatisfaction with the unreliability of the manual tapes and FIC level gauges led to their gradual replacement with the more reliable ENRAF gauges. An additional reason for switching to ENRAF gauges is that their electronic microprocessors can easily transmit additional and important level data to instrument buildings and to TMACS.

2.7.3.4 Functional Requirements. The level detection systems for all DSTs, including AWF tanks, and DCRTs shall provide level measurements prior to transfers to or from the tanks, and at specified intervals during the transfers, to support mass balance calculations.

The level detection systems for all DSTs, DCRTs, catch tanks, and SSTs that are not in intrusion prevention (interim isolation) status shall provide level measurements prior to waste transfers when the tanks are interconnected to the transfer route, and at specified intervals during the transfers.

The tank level detection systems shall measure waste levels with an accuracy of $\pm 1.3 \mathrm{~cm}$ ( $\pm 0.5 \mathrm{in}$.

2.7.3.5 System Evaluation. Tank level detection systems shall be calibrated annually to ensure compliance with the functional requirements stated above.

2.7.3.6 Supporting SSCs. Electrical power and instrument air for the tank level detection systems.

\subsubsection{Salt Well Flow Totalizers}

2.7.4.1 Safety Classification. The Salt Well Flow Totalizers are identified as safety-significant SSCs for the Subsurface Leak Remaining Subsurface accident.

2.7.4.2 Safety Function(s). Provide indication of the quantity (volume) of waste removed during the salt well process.

2.7.4.3 System Description. The salt well skid flow totalizer is a nonintrusive device (a magnetic flow element) which measures the quantity of waste liquid transferred by the salt well pump. Each salt well pump system is provided with a flow totalizer.

Salt well flow totalizers have a good performance history in Tank Farms with a mean time between failures measured in years. 
2.7.4.4 Functional Requirements. The flow totalizer instrument loop must be

- installed per manufacturers instructions

- operated within the design limits of the instrumentation system

- calibrated annually to within $\pm 5 \%$ of its full range.

2.7.4.5 System Evaluation. The salt well flow totalizer instrument loop must be calibrated annually to an accuracy of $\pm 5 \%$ of its full range.

2.7.4.6 Supporting SSCs. Electrical power for the flow totalizer instrumentation loop.

\subsection{UNPLANNED EXCAVATION/DRILLING IN POND/CRIB/DITCH (08)} accident.

No safety-class or safety-significant SSCs were identified for this

\subsection{CAUSTIC SPRAY LEAK (09)} accident.

No safety-class or safety-significant SSCs were identified for this

\subsection{SODIUM FIRE (10)}

\subsubsection{W Building}

2.10.1.1 Safety Classification. The 2727-W Building is identified as a safety-significant SSC for the Sodium Fire accident.

2.10.1.2 Safety Function(s).

(a) Building designed to withstand high winds

(b) Height of foundation above grade eliminates vehicle collisions as credible accident initiator

2.10.1.3 System Description. The 2727-W Building is a pre-fabricated metal structure installed on a concrete foundation wall extending $1.2 \mathrm{~m}(4 \mathrm{ft})$ above grade.

This building's chief vulnerability is to high winds; the building has survived 25 years without damage from wind forces, including a recorded wind speed above $128.7 \mathrm{~km} / \mathrm{h}(80 \mathrm{MPH})$.

2.10.1.4 Functional Requirements. The 2727-W Building and its foundation shall withstand

winds up to $112.7 \mathrm{~km} / \mathrm{h}(70 \mathrm{MPH})$

a vehicle collision.

2.10.1.5 System Evaluation. The 2727-W Building protects the five sodium tanks from normal hazards, and must be inspected annually for structural degradation from the configuration shown in design drawings. 
WHC-SD-WM-RD-057, Rev. 0

2.10.1.6 Supporting SSCs. None.

\subsection{MIXING OF INCOMPATIBLE MATERIAL - TOXIC VAPOR GENERATION (11)} accident.

No safety-class or safety-significant SSCs were identified for this

\subsection{MIXING OF INCOMPATIBLE MATERIAL - TANK PRESSURIZATION (12)}

\subsubsection{HEPA Filters (One stage required on 244-S, 244-TX, and 244-A)}

2.12.1.1 Safety Classification. The HEPA Filters for DCRTS 244-S, 244-TX, and 244-A are identified as safety-significant SSCs for the Mixing of Incompatible Material - Tank Pressurization accident.

2.12.1.2 Safety Function(s). Provide filtration of DCRT headspace gases prior to release.

2.12.1.3 System Description. The HEPA filters on DCRTs 244-A, 244-S, and 244-TX are designed to remove particulate matter from the ventilation system exhaust stream. HEPA filter elements are in a sealed structure having test ports capable of providing verification of system efficiency. HEPA filters are monitored to ensure that they are intact and do not create an excessive ventilation exhaust stream pressure drop.

HEPA filters have an excellent performance history in Tank Farm applications, with mean time between failures measured in years. Failure in this context means that radioactive particulate materials break through the filter media.

2.12.1.4 Functional Requirements. HEPA filter units shall remove at least $99.95 \%$ of $0.3 \mu \mathrm{m}$ (11.8 $\mu \mathrm{in})$ particles of an approved challenge aerosol from the ventilation exhaust flow stream.

2.12.1.5 System Evaluation. HEPA filters shall have their efficiency verified by aerosol challenge test at the time of installation and annually thereafter. HEPA filter assemblies are designed, fabricated, tested and inspected to ensure that their performance meets functional requirements.

\subsubsection{Supporting SSCs. None.}

\subsection{TANK FAILURE DUE TO EXCESSIVE LOADS (13)} accident.

No safety-class or safety-significant SSCs were identified for this

\subsection{FLAMMABLE GAS DEFLAGRATIONS (14)}

\subsubsection{DST/AWF Ventilation}


2.14.1.1 Safety Classification. The DST and AWF Primary Tank Ventilation Systems are identified as safety-class SSCs for the Flammable Gas

Deflagrations accident.

2.14.1.2 Safety Function(s). Maintain flammable gas concentrations in tank dome spaces, due to steady state releases, below $25 \%$ of the LFL.

2.14.1.3 System Description. Primary tank ventilation systems remove flammable gases from the vapor spaces in all tanks in Double-Shell Tank (DST) farms 241-AN, -AP, -AW, and -SY, and all tanks in Aging Waste Facility (AWF) tank farms 241-AY and $-A Z$. The systems draw outside air into the tanks where it mixes with and displaces the flammable gases produced by the waste. The air/gas mixture is then removed from the tanks, filtered to remove radioactive particulates, and exhausted to the environment. Specific details for each system are provided below.

Air enters the $A N, A P, A Y$, and $A Z$ tanks by inleakage through the central pump pit, and enters the tank through the pit drain line. Small gaps exist between the walls of the concrete pump pits and the concrete cover blocks. The amount of air flowing into the tanks and the tank vacuums are controlled by blocking the gaps and by adjusting the tank outlet butterfly valves. This process is repeated until the pressure in the tanks and air flow rates are within acceptable limits.

The SY tank farm tanks have HEPA filtered inlet stations which are connected to a primary tank riser. The pressure in the tank and air flow rates are regulated by inlet and outlet butterfly valves, which are adjusted until the pressures and flow rates are within acceptable limits. Additionally, the gaps between the pump pit walls and the cover blocks are sealed to prevent unfiltered leakage.

The tanks in AW tank farm have HEPA filtered inlet stations which contain constant flow devices. The constant flow devices are passive units that do not require support utilities and maintain a constant flow of air into the tanks. The working mechanism of the device is a floating orifice plate that opens or restricts the air inlet passage. The differential pressure across the orifice plate causes it to float. The orifice plates are interchangeable and calibrated to provide known combinations of pressure difference and flow. Similar to SY tank farm, other air inleakage passages into the primary tank have been sealed, and adjustment of the outlet butterfly valve aids in adjusting air flow and pressure. Unlike SY tank farm, however, the inlet butterfly valve is normally left in the full open position, and is closed only when the inlet HEPA filter is being replaced.

Active ventilation systems are vulnerable to drive train malfunctions such as loss of electrical power and control system trips from malfunctioning process monitors. Mean time between failures (MTBF) has typically been very short by industrial performance standards, and is measured in weeks. Equipment upgrades and improved maintenance procedures have proven that MTBF can be increased to a year or more.

2.14.1.4 Functional Requirements. The DST/AWF Ventilation Systems shall maintain a 0.06 to $1.49 \mathrm{kPa}(0.25$ to 6.0 inches water gauge [WG]) vacuum in the vapor spaces of all tanks. 
WHC-SD-WM-RD-057, Rev. 0

2.14.1.5 System Evaluation. Proper operation of the primary tank ventilation systems shall be verified daily.

2.14.1.6 Supporting SSCs. Electrical power.

\subsubsection{Primary Tank Leak Detection Systems}

2.14.2.1 Safety Classification. The Primary Tank Leak Detection Systems on DSTs and AWF tanks are identified as safety-class SSCs for the Flammable Gas Deflagrations accident.

2.14.2.2 Safety Function(s). Provide indication that corrective action is required to avoid accumulation and deflagration of waste gas in the annulus space.

2.14.2.3 System Description. Each DST and AWF primary tank leak detection system includes conductivity probes that detect the presence of liquid in the tank annulus, and a CAM that detects the presence of airborne radionuclides in the annulus ventilation exhaust stream. The systems are described below.

2.14.2.3.1 DST Farms 241-AN, AP, AW, and SY Conductivity Probes. Each double-shell tank is equipped with reel mounted Flake type adjustable conductivity probes installed in annulus risers. The liquid level is measured from gradations on a steel tape that is lowered into the annulus. The setting on each plummet is 0 to $2.54 \mathrm{~cm}$ ( 0 to $1.0 \mathrm{in.}$ ) above the annulus bottom. Liquid waste contact with the probe activates audible alarms, activates annunciator panel lights in the corresponding tank farm instrument buildings, and activates an alarm on CASS.

2.14.2.3.2 AWF Tank Farms 241-AY and AZ Conductivity Probes. Each AWF tank annulus is equipped with three leak detection probes. Each probe has 17 elements, located from $0.3 \mathrm{~cm}(0.13 \mathrm{in.})$ to $182.9 \mathrm{~cm}(72.0 \mathrm{in}$.$) from the$ bottom of the annulus. Data is obtained by rotating a selector switch for each tank through each of the 17 positions and manually recording the readings. The indicator lights and selector switches are located in the $A Y$ Farm and $A Z$ Farm instrument buildings, and the alarm sounds in the control building.

2.14.2.3.3 Annulus Ventilation CANs. The annulus ventilation system exhaust stack of each DST and AWF tank is equipped with a CAM. A vacuum pump extracts an air sample from the exhaust flowstream upstream of the HEPA filter housing and provides it to the CAM, where the sample is scanned for radionuclide particles. If a leak from the primary tank were to occur, the CAM would detect an increase in radioactive particulate activity, and if the radiation level measured by the CAM exceeded a preset level, an alarm would actuate.

Performance history of conductivity probes as annulus leak detectors is still being developed, but conductivity probes have performed reliably as transfer pit leak detectors for many years, with mean time between failures measured in years. CAMs have not generally performed satisfactorily, with mean time between failures measured in months. CAMs are vulnerable to loss of sample flow; low sample flow rate and other CAM malfunctions are normally detected and alarmed. 
WHC-SD-WM-RD-057, Rev. 0

2.14.2.4 Functional Requirements. The DST and AWF tank annulus conductivity probes must be able to detect a $2.54 \mathrm{~cm}$ (1.0 in.) deep accumulation of waste in the bottom of the DST annulus, and must provide an audible alarm signal and an annunciator panel light on detection of waste. The DST and AWF annulus ventilation system CAMs must operate continuously while the annulus ventilation system is operating, and must alarm when radiation levels exceeding a preset level are detected.

2.14.2.5 System Evaluation. The operability of the liquid waste detectors must be verified annually by circuit continuity verification, lamp illumination verification, and a system functional test. The annulus CAMs shall be calibrated annually, and the alarms and interlocks shall be functionally tested once a month. The CAMs shall be source checked weekly to verify appropriate system response.

2.14.2.6 Supporting SSCs. Electrical power for the conductivity probes, for the CAMs, for the associated alarm and annunciator systems, for the CAM cabinet heaters and fans, and for freeze protection heaters for the gas tubing.

\subsubsection{SST Ventilation}

2.14.3.1 Safety Classification. The SST Ventilation Systems are identified as safety-class SSCs for the Flammable Gas Deflagrations accident.

2.14.3.2 Safety Function(s). Maintain flammable gas concentrations in tank dome spaces, due to steady state releases, below $25 \%$ of the LFL.

2.14.3.3 System Description. Active ventilation systems remove flammable gases from the following SSTs.

- All tanks in Single-Shell Tank (SST) farm 241-SX (except for 241-SX-113 and -115 )

- SSTs $241-\mathrm{C}-105$ and -106

The remaining SSTs are equipped with passive ventilation systems. Active and passive systems are described below.

2.14.3.3.1 Active Ventilation. The systems draw outside air into the tanks through HEPA-filtered inlet stations. The air mixes with and displaces the flammable gases produced by the waste. The air/gas mixture is then removed from the tanks, filtered to remove radioactive particulates, and exhausted to the environment.

Active ventilation systems are vulnerable to drive train malfunctions, loss of electrical power, and control system trips due to malfunctioning process monitors. Mean time between failures (MTBF) has typically been very short by common industrial performance standards and has been measured in weeks. Equipment upgrades and improved maintenance procedures have proven that MTBF can be increased to a year or more.

2.14.3.3.2 Passive Ventilation. A passive ventilation consists of a filter housing, a HEPA filter, and a shutoff valve. The filter housing is fabricated with a riser adapter which allows the housing to be bolted directly 
to a 4-inch tank riser. The riser adapter contains a shutoff valve which is open during normal operation of the breather filter assembly. The shutoff valve is closed to isolate the HEPA filter from the tank so that aerosol testing of the filter can be completed. The valve is also used to isolate a filter that has failed the aerosol test, until the filter is replaced. The HEPA filter prevents the release of airborne radioactive particulates to the environment.

Passive ventilation systems allow flammable gases to be exhausted from the SSTs whenever the tank vapor space pressure exceeds atmospheric pressure. Conversely, the system allows air into the tank when atmospheric pressure exceeds the vapor space pressure. This influx of additional air dilutes the concentration of flammable gas in the vapor space.

Passive ventilation systems are vulnerable to damage by out of control vehicles, rainwater intrusion (at some tanks) and breather filters plugged by airborne dust.

\subsubsection{Functional Requirements}

2.14.3.4.1 Active Ventilation. SST active ventilation systems shall maintain a vacuum in the tank vapor space, relative to atmospheric pressure.

2.14.3.4.2 Passive Ventilation. A HEPA filtered flow path shall be provided to allow the vapor space pressure to be in equilibrium with the atmospheric pressure.

\subsubsection{System Evaluation}

2.14.3.5.1 Active Ventilation. Proper operation of the active ventilation systems shall be verified daily.

2.14.3.5.2 Passive Ventilation. The breather filter isolation valve must be checked weekly to ensure the flow path is unobstructed.

\subsubsection{Supporting SSCS}

2.14.3.6.1 Active Ventilation. Electrical power.

2.14.3.6.2 Passive Ventilation. None.

\subsubsection{DCRT Level Dip Tube Flow}

2.14.4.1 Safety Classification. The DCRT Level Dip Tubes are identified as safety-class SSCs for the Flammable Gas Deflagrations accident. This classification applies to their role in providing inlet air flow to the DCRTs, and not to their level detection function.

2.14.4.2 Safety Function(s). Prevent steady state accumulation of flammable gases.

2.14.4.3 System Description. The 244-BX DCRT currently stores radioactive waste and requires continuous ventilation to maintain flammable gas

concentrations below $25 \%$ of the LFL. Ventilation for 244-BX is provided by 
injecting instrument air into the installed weight factor dip tubes. The inlet air mixes with and dilutes the flammable gases in the vapor space of the tank. The 244-BX air/gas mixture is then swept from the tank by an active ventilation system, drawn through HEPA filters to remove radioactive particulate, and finally exhausted to the environment.

The remainder of the DCRTs (244-A, 244-CR, 244-S, 244-TX, and 244-U) and the 241-A-350 catch tank will require dip tube ventilation only when waste is stored in a tank. When waste is to be stored in these tanks, instrument air must be injected into the tank for ventilation, the air injection flow rate must be verified by the flow indicators, and the active ventilation system must be operating.

The performance history of the three dip tube air flowmeters for DCRT 244-BX has been satisfactory. Although they are fabricated from relatively fragile material, the flowmeters are protected from damage by airborne missiles by locating them inside the associated instrument building. A loss of flow is obvious, and necessary corrective actions can be taken immediately.

2.14.4.4 Functional Requirements. At least 2 of 3 dip tubes shall supply inlet air, at a minimum flow of $0.04 \mathrm{~m}^{3} / \mathrm{hr}\left(1.5 \mathrm{ft}^{3} / \mathrm{hr}\right)$ per tube, while there is waste in the tank. The DCRT dip tube flow indicators shall have a minimum calibratable range of $0 \mathrm{~m}^{3} / \mathrm{hr}$ to $0.08 \mathrm{~m}^{3} / \mathrm{hr}\left(0 \mathrm{ft}^{3} / \mathrm{hr}\right.$ to $\left.3 \mathrm{ft}^{3} / \mathrm{hr}\right)$.

2.14.4.5 System Evaluation. The dip tube flow indicators used to verify ventilation flow for 244-BX DCRT (FI-1, FI-2, and FI-3) shall be calibrated annually. Similarly, the dip tube flow indicators for 244-A, 244-CR, 244-S, 244-TX, 244-U, and 241-A-350 must be calibrated and verified to meet the functional requirements stated above before waste can be stored in those tanks.

2.14.4.6. Supporting SSCs. Dry instrument air from a compressed air system for dip tube flow.

\subsubsection{TK-002 244-AR Level Dip Tube Flow}

2.14.5.1 Safety Classification. The 244-AR Vault TK-002 Level Dip Tubes are identified as safety-class SSCs for the Flammable Gas Deflagrations accident. This classification applies to their role in providing inlet air flow to the tank, and not to their level detection function.

2.14.5.2 Safety Function(s). Prevent steady state accumulation of flammable gases.

2.14.5.3 System Description. Lag Storage Tank TK-002 in the 244-AR facility currently stores radioactive waste, and requires continuous ventilation to maintain flammable gas concentrations below $25 \%$ of the LFL. Ventilation for TK-002 is provided by injecting instrument air into the installed weight factor dip tubes. The inlet air mixes with and dilutes the flammable gases in the vapor space of the tank. The TK-002 air/gas mixture is then displaced from the tank, passed through HEPA filters to remove radioactive particulate, and finally exhausted to the environment by natural convection. 
WHC-SD-WM-RD-057, Rev. 0

The performance history of the three TK-002 dip tube air flowmeters has been satisfactory. Although they are fabricated from relatively fragile material, the flowmeters are protected from damage by airborne missiles by locating them inside the associated instrument building. A loss of flow is obvious, and necessary corrective actions can be taken immediately.

2.14.5.4 Functional Requirements. The dip tubes shall provide a minimum inlet air flow of $0.08 \mathrm{~m}^{3} / \mathrm{hr}\left(3 \mathrm{ft}^{3} / \mathrm{hr}\right)$ to 244-AR tank TK-002 while waste remains in the tank. The dip tube flow indicators shall have a minimum cal ibratable range of $0 \mathrm{~m}^{3} / \mathrm{hr}$ to $0.08 \mathrm{~m}^{3} / \mathrm{hr}\left(0 \mathrm{ft}^{3} / \mathrm{hr}\right.$ to $\left.3 \mathrm{ft}^{3} / \mathrm{hr}\right)$. The range is based on an assumption that the flow will be provided by a minimum of two dip tubes, each providing a minimum of $0.04 \mathrm{~m}^{3} / \mathrm{hr}\left(1.5 \mathrm{ft}^{3} / \mathrm{hr}\right)$.

2.14.5.5 System Evaluation. The dip tube flow indicators used to verify ventilation flow for TK-002 shall be calibrated annually.

2.14.5.6 Supporting SSCs. Instrument air from a compressed air system for dip tube flow.

\subsubsection{SY-101 Mixer Pump}

2.14.6.1 Safety Classification. The SY-101 Mixer Pump is identified as a safety-class SSC for the Flammable Gas Deflagrations accident.

2.14.6.2 Safety Function(s). Reduce the frequency of a flammable gas deflagration by mixing, releasing flammable gases generated and trapped in the waste.

2.14.6.3 System Description. A mixture of gases (including hydrogen, nitrous oxide, ammonia, nitrogen and methane) is produced in the tank waste by chemical reactions and radiolytic decomposition. The gas is capable of deflagrating with air (or with certain of the components [nitrous oxide and carbon monoxide] of the gas mixture) if the gas concentration exceeds the lower flammability limit (LFL). A significant fraction of the gas accumulates in the non-convecting (NC) waste layer at the bottom of the tank. The imbalance between gas production rate and gas release rate, if prolonged, causes the NC layer to expand until its density is lower than that of the waste layer above. The density inversion results in sudden tank waste "rollovers," the release of accumulated gases (a "gas release event" or GRE), and flammable gas concentrations in the headspace which may exceed the LFL.

The mixer pump mixes lower-density convective layer material into the non-convecting (NC) layer. Routine mixer pump operation for short time periods results in a controlled release of gas at concentrations well below the established safety limits; continuous operation of the mixer pump is not required. Because the build-up of gas in the waste results in a rising level of waste in the tank, mixer pump operational performance is indirectly monitored by how well the waste level can be maintained in the safe range, as defined by LA-UR-92-3196, A Safety Assessment for Proposed Pump Mixing operations to Mitigate Episodic Gas Releases in Tank 241-SY-101: Hanford Site, Richland, Washington (referred to herein as the Safety Assessment). Safety Assessment documents conditions for safe pump operation, including limits on time of operation and energy input to the waste. 
The mixer pump is incapable of agitating all of the liquid and sludge contained in Tank 241-SY-101, particularly the sludge close to the tank sidewall and tank bottom; future waste rollovers and GREs cannot be therefore precluded entirely, particularly if waste properties change. Routine mixer pump operation since the pump was installed, however, has succeeded in preventing dome space flammable gas concentrations from exceeding $25 \%$ of the LFL. Mixer pump operation agitates the waste stored in the tank and releases the accumulated gases at volumetric rates which can be safely released to the atmosphere by the tank's primary ventilation system.

2.14.6.4 Functional Requirements. The mixer pump must be capable of agitating the stored waste and releasing flammable gases produced and trapped in the waste to the tank headspace. The pump is required to agitate a sufficiently large fraction of the waste at intervals such that the tank ventilation system can routinely maintain the gas concentration in the tank headspace below $25 \%$ of the LFL. The pump shali be capable of varying the outlet nozzle orientation. The pump, and portions of its control and support systems located within the tank, are required to operate in a potentially flammable gas environment. They must not contribute to the risk of gas combustion or deflagration inside Tank 241-SY-101, either through electrical sparking or heating, or by mechanical malfunctions.

2.14.6.5 System Evaluation. The mixer pump is functionally tested each time it is operated (several times each week). Functional tests and loop calibrations of the various instruments for monitoring pump operation shall be performed according to established schedules.

2.14.6.6 Supporting SSCs. Electrical power for controls and mixer pump drive motor operation, nitrogen purge system.

\subsubsection{SY-101 Hydrogen Monitor}

2.14.7.1 Safety Classification. The SY-101 Hydrogen Monitor is identified as a safety-class SSC for the Flammable Gas Deflagrations accident.

2.14.7.2 Safety Function(s). Provide indication and alarm for hydrogen gas concentration in the 241-SY-i01 vapor space to the operations staff. Provide interlock to stop mixer pump operation if $\mathrm{H}_{2}$ concentration reaches $0.75 \%$ (7500 $\mathrm{ppm}$ ) by volume.

2.14.7.3 System Description. The 241-SY-101 standard hydrogen monitoring system (SHMS) is designed to measure and record hydrogen concentrations in mixtures with air and other gases, including gas mixtures with flammable compositions, and to do so without igniting the gas mixture. The system is also designed to provide local and remote alarms, and an interlock to stop mixer pump operation, when the hydrogen concentration reaches a preset level. The alarms automatically reset when the hydrogen concentration drops below the preset alarm level.

2.14.7.4 Functional Requirements. The SHMS shall be designed to measure hydrogen concentrations in the range $0 \%$ to $5.0 \% \mathrm{H}_{2}$ by volume in tank atmospheres containing various mixtures with other gases such as air, nitrous oxide, ammonia, carbon dioxide, carbon monoxide, and water vapor. 
WHC-SD-WM-RD-057, Rev. 0

The SHMS shall provide local and remote alarms when the hydrogen concentration in the 241-SY-101 tank vapor space reaches a preset level. The alarms shall automatically reset when the hydrogen concentration drops below the preset level. The SHMS shall actuate an interlock to stop the mixer pump when the hydrogen concentration reaches $0.75 \%$ (7500 ppm) $\mathrm{H}_{2}$ by volume.

SHMS components external to the $S \gamma-101$ tank must operate in an outdoor environment with temperatures ranging from $-29^{\circ} \mathrm{C}$ to $49^{\circ} \mathrm{C}\left(-20^{\circ} \mathrm{F}\right.$ to $\left.120^{\circ} \mathrm{F}\right)$, a relative humidity of $5 \%$ to $100 \%$, and a maximum wind speed of $129 \mathrm{~km} / \mathrm{h}$ ( 80 MPH). The gas sampling subsystem shall obtain samples from a location within the tank internal environment with a temperature range of $10^{\circ} \mathrm{C}$ to $100^{\circ} \mathrm{C}\left(50^{\circ} \mathrm{F}\right.$ to $\left.212^{\circ} \mathrm{F}\right)$, a pressure range of $-3.0 \mathrm{kPa}$ to $14.9 \mathrm{kPa}(-12$ to 60 inches water gauge), and a $\mathrm{pH}$ range of 8.0 to 12.0 .

2.14.7.5 System Evaluation. The SHMS must be routinely tested and calibrated with standard gases. The testing program must include functional tests of the SHMS alarm and mixer pump run interlock functions.

2.14.7.6 Supporting SSCs. Electrical power for normal operation.

\subsubsection{SY-101 Level Monitoring System}

2.14.8.1 Safety Classification. The SY-101 Level Monitoring System is identified as a safety-class SSC for the Flammable Gas Deflagrations accident.

2.14.8.2 Safety Function(s). Provide indication of tank level which directs operation of the mixer pump.

2.14.8.3 System Description. The Tank 241-SY-101 level monitoring system provides information to support mixer pump operating controls. The tank is equipped with a surface level monitoring system that includes an ENRAF gauge, a radar gauge, an FIC, and a manual tape as level detection devices. Level data are automatically provided to TMACS and DACS. The mixer pump Test Review Group (TRG) uses the data received from the FIC to determine when bumping (short-term startups) and operation of the pump can safely be performed.

2.14.8.4 Functional Requirements. The 241-SY-101 level monitoring system shall measure the surface level of the waste in the tank and shall transmit the data to TMACS and DACS. It shall be capable of measuring tank levels up to $10.72 \mathrm{~m}$ (422 in.). The system shall provide measurements prior to mixer pump operation.

2.14.8.5 System Evaluation. The level monitoring system shall be calibrated annually to ensure compliance with the functional requirements stated above.

2.14.8.6 Supporting SSCs. Electrical power and instrument air for the level monitoring system. 


\subsubsection{SY-101 Pressure Monitoring System}

2.14.9.1 Safety Classification. The SY-101 Pressure Monitoring System is identified as a safety-class SSC for the Flammable Gas Deflagrations accident.

2.14.9.2 Safety Function(s). Provide indication and alarm for tank dome pressure. Provide interlock to stop mixer pump operation on high pressure.

2.14.9.3 System Description. Tank pressure is monitored continuously with a pressure-sensing tube inserted in the tank dome space and a Foxboro pneumatic transmitter. Instrument air is supplied to the transmitter, and depending upon the tank pressure sensed by the tube, a 20.7 - $103.4 \mathrm{kPa}(3-15 \mathrm{psig})$ signal is transmitted to the $271-S Y$ instrument building. The associated instruments include a high pressure alarm and a strip chart recorder.

The multi-function instrument tree (MIT), which measures temperature and vapor samples, also includes a pressure output to the Data Acquisition Control System (DACS) facility. The MIT can be used as a backup for pressure readings.

The pressure monitoring system initiates an alarm when the tank dome pressure reaches a preset limit, and initiates an interlock to shut down the mixer pump when the tank dome pressure reaches $-0.25 \mathrm{kPa}(-1.0 \mathrm{in}$. WG).

2.14.9.4 Functional Requirements. The pressure monitoring system for 241-SY101 shall be capable of sensing tank pressure over the full range of expected values. The system shall initiate an alarm when the pressure reaches a preset limit, and shall actuate an interlock to stop mixer pump operation when the pressure reaches $-0.25 \mathrm{kPa}(-1.0 \mathrm{in}$. WG).

2.14.9.5 System Evaluation. The pressure monitor shall be calibrated and the alarm and interlock functions tested annually.

2.14.9.6 Supporting SSCs. Electrical power, instrument air, DACS.

\subsubsection{SY-101 Ventilation Flowmeter}

2.14.10.1 Safety Classification. The SY-101 Ventilation Flowmeter is identified as a safety-class SSC for the Flammable Gas Deflagrations accident.

2.14.10.2 Safety Function(s). Provide indication and alarm for ventilation flow rate. Provide interlocks to stop mixer pump operation on high or low flow rate.

2.14.10.3 System Description. The ventilation flow rate for tank SY-101 is sensed by a flow element which is located in the ventilation header. The flow element is connected to two flow indicator transmitters (FITs) which provide alarm capability for high and low ventilation flow rates. The FITs provide local readout of the $101-5 Y$ ventilation flow rate and transmit the readings to TMACS and the DACS trailer. The FITs are identical with the exception of the alarm and interlock setpoints. The lower setpoints indicate insufficient air flow through the tank to maintain flammable gas concentrations below 25\% LFL. The higher setpoints indicate a gas release event may be occurring. In both cases, shutdown of the mixer pump is necessary to prevent ignition of the gas. 
WHC-SD-WM-RD-057, Rev. 0

2.14.10.4 Functional Requirements. The flow monitoring system shall operate continuously while the mixer pump is operating. The two FITs (a low range and a high range) shall alarm at the preset levels. The low range FIT shall actuate an interlock to shut down the mixer pump when the flow rate decreases to $400 \mathrm{cfm}$. The high range FIT sha11 actuate an interlock to shut down the mixer pump when the flow rate reaches $700 \mathrm{cfm}$.

2.14.10.5 System Evaluation. The flow monitoring system shall be calibrated and the alarm and interlock functions tested annually. Both FITs must be functional and online prior to and during mixer pump operation.

2.14.10.6 Supporting SSCs. Electrical power, DACS.

\subsubsection{SY-101 Ammonia Detection Systems}

2.14.11.1 Safety Classification. The SY-101 Ammonia Detection Systems are identified as safety-class SSCs for the Flammable Gas Deflagrations accident.

2.14.11.2 Safety Function(s). Detect ammonia in the tank headspace/exhaust gas and alarm on the Data Acquisition Control System (DACS) when a high level of ammonia exists.

2.14.11.3 System Description. The ammonia detection system consists of two different types of transducers described below.

- The Fourier Transfer Infra-Red (FTIR) spectrometer shoots a concentrated laser beam, operating in the infrared spectrum, through a cell containing a sample of the vapor stream from the tank exhaust. This sets up an interference pattern in conjunction with a Nicholson interferometer. The location and energy of the peaks determines the concentration of ammonia present. The detectors sample four times per hour and have a range of 10 to $10,000 \mathrm{ppm}$ with an accuracy of $\pm 10 \%$.

- The Breurl \& Kjaer (B \& K) photo-acoustic detector monitors the exhaust gas from the tank farm ventilation system stack. A sample is collected in a chamber which is bombarded with a focused IR source; this excites the ammonia molecules and detects the acoustic vibrations associated with the presence of ammonia. The detectors sample ten times per hour and have a range of 10 to $30,000 \mathrm{ppm}$ with an accuracy of $\pm 10 \%$.

Both detectors provide alarms when high levels of ammonia are detected. There are no automatic interlocks associated with the system.

2.14.11.4 Functional Requirements. The ammonia detection system shall be capable of sensing ammonia concentrations up to $3000 \mathrm{ppm}$, and must be capable of operation during gas release events. The system shall alarm when preset levels of ammonia concentration are reached.

2.14.11.5 System Evaluation. The ammonia detectors must be installed and operated per the manufacturers' instructions. The FTIR shall be functionally tested once per year. The $B$ \& $K$ shall be calibrated every 120 days using a standard gas mixture, and may be verified by comparison with FTIR in $1 a b$. 
The ammonia detection systems as installed are both redundant and diverse; thus corroboration of a specific reading can be either verified or disputed. The detection systems are calibrated and/or verified to be functional on a regular basis, which ensures that the value read or stored truly represents the conditions within the vapor space of the tanks.

2.14.11.6 Supporting SSCs. Electrical power for the detection systems, the climate control for the systems, and the DACS.

\subsubsection{SY-101 Temperature Monitoring System}

2.14.12.1 Safety $\mathrm{Cl}$ assification. The SY-101 Temperature Monitoring System is identified as a safety-class SSC for the Flammable Gas Deflagrations accident.

2.14.12.2 Safety Function(s). Provide indication and alarm for tank waste temperature. Provide interlock to stop mixer pump operation on high temperature.

2.14.12.3 System Description. The 241-SY-101 waste temperature monitoring system includes two thermocouple trees and two multi-function instrument trees (MITs), and provides temperature information to the Tank Monitoring and Control System (TMACS).

The thermocouple tree is a temperature measuring device equipped with $\mathrm{J}$, $K$, or $L$ thermocouples (temperature elements). Each tree consists of a steel pipe with 4 to 18 thermocouples. The thermocouple tree is equipped with temperature detectors placed at $61.0 \mathrm{~cm}(2 \mathrm{ft})$ intervals within the tank (the distance of the lowest detector from the tank bottom varies from tank to tank). The MIT includes thermocouples as well as vapor probe chambers for sampling. The MIT contains 27 thermocouples evenly spaced at different elevations from the bottom of the tank to the tank vapor space. The MIT temperature output signals are connected to TMACS.

The temperature monitoring system actuates an alarm when any temperature detector senses a temperature at or above a preset limit, and actuates an interlock to shut down the mixer pump when any temperature detector senses a temperature at or above $57.2^{\circ} \mathrm{C}\left(135^{\circ} \mathrm{F}\right)$.

The temperature monitoring system for Tank 241-SY-101 is considered reliable. Multiple thermocouples are installed in multi-function instrument trees in the tank, so that fajlure of a few of the thermocouples does not prevent measurement of waste temperatures. Electrical power interruptions may interfere with data transmission to TMACS, but temperatures can be read locally, if required, by means of calibrated millivoltmeters connected temporarily to the thermocouple wires.

2.14.12.4 Functional Requirements. The 241-SY-101 temperature monitoring system shall be capable of detecting and displaying tank waste temperature data in the range from $10^{\circ} \mathrm{C}$ to $121.1^{\circ} \mathrm{C}\left(50^{\circ} \mathrm{F}\right.$ to $\left.250^{\circ} \mathrm{F}\right)$. The system shall provide an alarm signal when the waste temperature reaches the preset level during mixer pump operation. The system shall provide an interlock to shut down the mixer pump when the waste temperature reaches $57.2^{\circ} \mathrm{C}\left(135^{\circ} \mathrm{F}\right)$. 
2.14.12.5 System Evaluation. The operability of the waste temperature monitoring system shall be verified annualiy by functional test to assure that each temperature display is within $\pm 2.8^{\circ} \mathrm{C}\left( \pm 5^{\circ} \mathrm{F}\right)$ of the temperature read locally by a hand held temperature monitoring instrument at the thermocouple output signal connection. The alarm and interlock functions shall be tested annually.

2.14.12.6 Supporting SSCs. Electrical power for the alarm and interlock signals.

\subsection{ORGANIC SOLVENT FIRE (15)} accident.

No safety-class or safety-significant SSCs were identified for this

\subsection{IN-TANK FUEL FIRE/DEFLAGRATION (16)} accident .

No safety-class or safety-significant SSCs were identified for this

\subsection{ORGANIC SALT - NITRATE REACTION (17)}

No safety-class or safety-significant SSCs were identified for this accident.

\subsection{SURFACE LEAK RESULTING IN POOL (18)}

\subsubsection{Transfer Leak Detection Systems}

2.18.1.1 Safety Classification. The Transfer Leak Detection Systems are identified as safety-class SSCs for the Surface Leak Resulting in Pool accident.

\subsubsection{Safety Function(s).}

2.18.1.2.1 For Waste Transfer Pits. Detect leak inside pit; limit volume of waste spilled to pit.

\subsection{For Process Pits. Prevent overflow.}

2.18.1.2.3 For Cleanout Boxes. Detect leak, shut off transfer pump before cleanout box overflows.

2.18.1.2.4 For Pits Interfacing with OGT Lines. Detect leak, shutdown transfer before interfacing pit(s) overflow.

2.18.1.3 System Description. Transfer-associated structures, which include pits, sumps, and cleanout boxes, are provided with leak detectors located in the lowest part of the structure. The leak detectors have electrodes at different electrical potentials which are short circuited by a conductive 
medium (i.e., liquid waste) and cause a change in state of the monitoring circuitry. When liquid waste short circuits the leak detector electrodes, an al arm is generated, and, in some systems, associated interlock circuitry is actuated and the transfer pump is shut down. The wiring between the leak detector and the control panel is electrically supervised. The control and alarm functions associated with the leak detector are testable.

Conductivity probes have performed reliably as transfer pit leak detectors for many years, with mean time between failures measured in years.

2.18.1.4 Functional Requirements. A 1eak detector must be capable of detecting a $2.54 \mathrm{~cm}$ ( 1 in.) deep waste leak. The leak detection system is required to activate an alarm, or an interlock to prevent or stop operation of the transfer pump, when a leak is detected.

2.18.1.5 System Evaluation. The operation of each pit leak detector and its associated alarm and control circuitry shall be verified prior to each transfer of waste through a route connected with the pit, and at least annually. The alarm feature annunciation shall be verified prior to each waste transfer through a route connected with the pit. The pit leak detection alarm circuitry shall be tested periodically to verify that a loss of alarm circuit continuity will result in an alarm.

2.18.1.6 Supporting SSCs. Electrical power for alarm and control circuitry associated with the leak detector.

\subsubsection{Primary Tank Leak Detection Systems}

2.18.2.1 Safety Classification. The Primary Tank Leak Detection Systems on DSTs and AWF tanks are identified as safety-class SSCs for the Surface Leak Resulting in Pool accident.

2.18.2.2 Safety Function(s). Detect misroutes into the annulus of DSTs and AWF tanks.

2.18.2.3 System Description. Each DST and AWF primary tank leak detection system includes conductivity probes that detect the presence of liquid in the tank annulus, and a CAM that detects the presence of airborne radionuclides in the annulus ventilation exhaust stream. The systems are described below.

2.18.2.3.1 DST Farms 241-AN, AP, AW, and SY Conductivity Probes. Each DST is equipped with reel mounted Flake type adjustable conductivity probes installed in annulus risers. The liquid level is measured from gradations on a steel tape that is lowered into the annulus. The setting on each plummet is 0 to $2.54 \mathrm{~cm}$ (0 to $1.0 \mathrm{in}$.) above the annulus bottom. Liquid waste contact with the probe activates audible alarms, annunciator panel lights in the corresponding tank farm instrument buildings, and an alarm on CASS.

2.18.2.3.2 Aging Waste Farms 241-AY, AZ. Each AWF tank annulus is equipped with three leak detection probes. Each probe has 17 elements, located from $0.3 \mathrm{~cm}(0.13 \mathrm{in.})$ to $182.9 \mathrm{~cm}(72.0 \mathrm{in.})$ from the bottom of the annulus. Data is obtained by rotating a selector switch for each tank through each of the 17 positions and manually recording the readings. The indicator 
WHC-SD-WM-RD-057, Rev. 0

lights and selector switches are located in the AY Farm and AZ Farm instrument buildings, and the alarm sounds in the control building.

2.18.2.3.3 Annulus Ventilation CAMs. The annulus ventilation system exhaust stack of each DST and AWF tank is equipped with a CAM. A vacuum pump extracts an air sample from the exhaust flowstream upstream of the HEPA filter housing and provides it to the CAM, where the sample is scanned for radionuclide particles. If a leak from the primary tank were to occur, the CAM would detect an increase in radioactive particulate activity, and if the radiation level measured by the CAM exceeded a preset level, an alarm would actuate.

Performance history of conductivity probes as annulus leak detectors is lacking, but conductivity probes have performed reliably as transfer pit leak detectors for many years, with mean time between failures measured in years. CAMs have not generally performed satisfactorily, with mean time between failures measured in months. CAMs are vulnerable to loss of sample flow; low sample flow rate and other CAM malfunctions are normally detected and al armed.

2.18.2.4 Functional Requirements. The annulus conductivity leak detection system must be able to detect a $2.54 \mathrm{~cm}(1.0 \mathrm{in}$.$) deep accumulation of waste$ in the bottom of the DST annulus, and must provide an audible alarm signal and an annunciator panel light on detection of waste. The DST and AWF tank annulus ventilation system CAMs must operate continuously while the annulus ventilation system is operating, and must alarm when radiation levels exceeding a preset level are detected.

2.18.2.5 System Evaluation. The operability of the liquid waste detectors must be verified annually by circuit continuity verification, lamp illumination verification, and a system functional test. The annulus CAMs shall be calibrated annually, and the alarms and interlocks shall be functionally tested once a month. The CAMs shall be source checked weekly to verify appropriate system response.

2.18.2.6 Supporting SSCs. Electrical power for the conductivity probes, for the CAMs, for the interlocks and alarms, for the CAM cabinet heaters and fans, and for freeze protection heaters for the gas tubing.

\subsubsection{Pressure Switch Interlocks or Alarms (Water Service Lines)}

2.18.3.1 Safety Classification. The Pressure Switch Interlocks or Alarms (Water Service Lines) are identified as safety-class SSCs for the Surface Leak Resulting in Pool accident.

2.18.3.2 Safety Function(s). Prevent backflow of waste into service water system where leak could form surface pool by overflowing surface pits/buildings or leaking from above grade piping.

2.18.3.3 System Description. A pressure at, or above, the set point of the pressure switch results in a change in condition of a set of control contacts which are connected into the liquid waste transfer pump motor control circuitry. This results in the actuation of an alarm, or of an interlock to stop the transfer pump. When the transfer system is being flushed, the pressure of the service water flush is above the pressure switch set point, 
thus ensuring the transfer pump is in the shut down condition. During water flushing operations the pressure switch is valved into the transfer piping system. During waste transfer operations the pressure switch is valved out of the transfer piping system.

Pressure switches in service water supply lines and their interlocks with waste transfer pumps are considered reliable with mean time between failures estimated in years.

2.18.3.4 Functional Requirements. The pressure switch is required to actuate an alarm, or to actuate an interlock to prevent or stop operation of the transfer pump, when a high pressure is detected from the service water system.

2.18.3.5 System Evaluation. The pressure switch must be operated within the manufacturers' design limits. The pressure switch must be calibrated annually. The alarm function, and the interlock function where provided, must be tested annually.

2.18.3.6 Supporting SSCs. Electrical power for the pressure switch/transfer pump motor control system.

\subsubsection{OGT Encasement and Connections}

2.18.4.1 Safety Classification. The overground transfer system (OGT)

Encasement and Connections are identified as safety-class SSCs for the Surface Leak Resulting in Pool accident.

2.18.4.2 Safety Function(s). Provide secondary confinement for leaks from primary line; route leak from primary line back to process pit.

2.18.4.3 System Description. OGT systems are temporary structures; they are designed, built, tested, used to transfer waste, flushed, and then

disassembled. After disassembly, the OGT components are either discarded as solid waste or stored for future use. The design of every 0GT system is traceable to engineering design documents, which are kept current until the system is disassembled. Some of the components of an existing OGT system may be re-used in later OGT system assemblies, but this is not a requirement. OGT systems, because they are arrangements of temporary piping, are not 1 isted in this discussion, and are described only in general terms.

The principal safety feature of an OGT system is the secondary encasement pipe assembly, which jackets and provides a confinement for the primary waste transfer pipe. If the inner OGT pipe leaks, the encasement of the OGT system will confine the leaked waste and safely route it to a covered pit at the inlet or outlet end of the OGT system.

For corrosion resistance, the encasement sections are typically fabricated in short length flanged sections from 3 in. schedule 40 stainless steel (304L) pipe. Typical encasement pipe sections include straight runs, 90,45 , and $22 \frac{3}{2}$ degree long-radius elbows, and other special bends as needed to construct the piping route.

Encasements for OGT lines have performed reliably whenever temporary OGT systems have been assembled and used. 
WHC-SD-WM-RD-057, Rev. 0

2.18.4.4 Functional Requirements. The OGT Encasement and Connections system shall confine waste leaked from the primary pipe to the annulus between the encasement and the primary pipe, and shall divert the leaked waste to a pit at either end of the OGT Encasement and Connections system.

2.18.4.5 System Evaluation. Prior to a waste transfer, the integrity of an OGT encasement system must be confirmed by a pneumatic pressure test. The pneumatic test also confirms the integrity of the encased portions of the primary transfer line.

An OGT encasement system must be visually examined for damage or loss of integrity before a concrete shielding system section is set in place, and before waste transfer operations begin.

The position of the seal loop (encasement drain) valve at each end of the OGT transfer system must be verified before waste transfer operations can commence; at least one of the two seal loop valves, and preferably both, must be open. The seal loop drain hoses must be configured in accordance with design drawings. Waste in the encasement drain hose will ultimately overflow the seal loop and drain to the pit floor for detection by the pit leak detectors.

\subsubsection{Supporting SSCs. None.}

\subsubsection{OGT Concrete Shielding System}

2.18.5.1 Safety Classification. The OGT Concrete Shielding System is identified as a safety-class SSC for the Surface Leak Resulting in Pool accident.

2.18.5.2 Safety Function(s). Protect OGT from vehicle impacts (if vehicle controls not implemented).

2.18.5.3 System Description. OGT systems are temporary structures; they are designed, built, tested, used to transfer waste, flushed, and then disassembled. After disassembly, the OGT components are either discarded as solid waste or stored for future use. The design of every OGT system is traceable to engineering design documents, which are kept current until the system is disassembled. Some of the components of an existing OGT system may be reused in later OGT system assemblies, but this is not a requirement. OGT systems, because they are arrangements of temporary piping and other supporting components, are not listed in this discussion, and are described only in general terms.

Engineered steel-reinforced concrete radiation shields are emplaced over the assembled OGT encasement systems. The concrete shield section thickness varies according to the amount of radiation shielding required for the system. The concrete shields protect the OGT system from vehicle impacts, which have the potential for causing waste leaks of the type described in the accident analysis.

The OGT concrete shielding system components are susceptible to rough handling damage, e.g., by being dropped or by the impact of a heavy vehicle. Any structurai damage is immediately obvious, however, and damaged components 
WHC-SD-WM-RD-057, Rev. 0

of the OGT concrete shielding system are either repaired before installation or discarded.

2.18.5.4 Functional Requirements. The OGT Concrete Shielding System installation shall conform to its engineering design documents. The system shall be capable of preventing damage to the OGT encasement and connections from vehicle impact.

2.18.5.5 System Evaluation. When the concrete shielding system sections are not installed over the OGT encasement system, access to the system by personnel and vehicles must be administratively controlled. An installed OGT concrete shielding system must be visually examined for damage or loss of integrity before a waste transfer operation begins.

\subsubsection{Supporting SSCs. None.}

\subsubsection{Tank Level Detection Systems}

2.18.6.1 Safety Classification. The Tank Level Detection Systems are identified as safety-significant SSCs for the Surface Leak Resulting in Pool accident.

2.18.6.2 Safety Function(s). Support periodic mass balances during transfers. Indicate tank level increase due to service water line break.

2.18.6.3 System Description. Each DST, SST, DCRT, and catch tank is equipped with a surface level detection system. Each system includes at least one level detector, which may be a manual tape, an FIC, an ENRAF gauge, or a set of dip tubes. Each DST has either an FIC or an ENRAF gauge and a manual tape backup; most SSTs, DCRTs, and catch tanks have a single level detector. Level data can be locally read, and are automatically or manually provided to TMACS and/or CASS. The 241-SY-101 level detection system contains both an FIC and an ENRAF gauge, and provides data to DACS as well as to TMACS. Level increases and decreases are detected by comparison of current level measurements with previous measurements. Mass balance discrepancies are detected by calculation using readings obtained at specified intervals during a waste transfer.

Five types of tank level detection systems are employed in Tank Farms. A dissatisfaction with the unreliability of the manual tapes and FIC level gauges led to their gradual replacement with the more reliable ENRAF gauges. An additional reason for switching to ENRAF gauges is that their electronic microprocessors can easily transmit additional and important level data to instrument buildings and to TMACS.

2.18.6.4 Functional Requirements. The level detection systems for all DSTs, including AWF tanks, and DCRTs shall provide level measurements prior to transfers to or from the tanks, and at specified intervals during the transfers, to support mass balance calculations.

The level detection systems for all DSTs, DCRTs, catch tanks, and SSTs that are not in intrusion prevention (interim isolation) status shall provide level measurements prior to waste transfers when the tanks are interconnected 


$$
\text { WHC-SD-WM-RD-057, Rev. } 0
$$

to the transfer route, and at specified intervals during the transfers, to detect misroutes.

The level detection systems for all DSTs, DCRTs, catch tanks, and SSTs that are not in intrusion prevention status shall provide level measurements at specified intervals to detect a service water leak into the tank.

The tank level detection systems shall measure waste levels with an accuracy of $\pm 1.3 \mathrm{~cm}( \pm 0.5 \mathrm{in.})$

2.18.6.5 System Evaluation. Tank level detection systems shall be calibrated annually to ensure compliance with the functional requirements stated above.

2.18.6.6 Supporting SSCs. Electrical power.

\subsubsection{Salt Well Flow Totalizers}

2.18.7.1 Safety Classification. The Salt Well Flow Totalizers are identified as safety-significant SSCs for the Surface Leak Resulting in Pool accident.

2.18.7.2 Safety Function(s). Support periodic mass balances during transfers.

2.18.7.3 System Description. The salt well skid flow totalizer is a nonintrusive device (a magnetic flow element) which measures the quantity of waste liquid transferred by the salt well pump. Each salt well pump system is provided with a flow totalizer.

Salt well flow totalizers have a good performance history in Tank Farms with a mean time between failures measured in years.

2.18.7.4 Functional Requirements. The flow totalizer instrument loop must be:

- Installed per manufacturers instructions

- Operated within the design limits of the instrumentation system

- Calibrated annually to within $\pm 5 \%$ of its full range.

2.18.7.5 System Evaluation. The salt well flow totalizer instrument loop must be cal ibrated annually to an accuracy of $\pm 5 \%$ of its full range. Instrument loop calibration must be done by trained personnel using approved procedures.

2.18.7.6 Supporting SSCs. Electrical power for the flow totalizer instrumentation loop.

\subsubsection{Transfer System Covers}

2.18.8.1 Safety Classification. The Transfer System Covers, including waste transfer pit covers and cleanout box covers, are identified as safetysignificant SSCS for the Surface Leak Resulting in Pool accident. 
2.18.8.2 Safety Function(s). Limit release of aerosols generated by splatter inside the pit; limit shine and skyshine dose to onsite receptor.

2.18.8.3 System Description. Permanent covers are typically heavy sections of reinforced concrete, although some covers are made from steel plate per their design documentation. Temporary covers are discouraged, but if used, must be fabricated according to released engineering documents and meet the functional requirements of permanent covers. Appendix $B$ of this document lists the waste transfer system pit covers that are safety-significant SSCs during a waste transfer operation which includes the pit on the active transfer route.

Concrete transfer pit covers have demonstrated excellent durability in Tank Farm service, even though they are vulnerable to rough handling during removal and replacement. Appropriate lifting equipment is used to remove and replace covers, and all lifts are performed to approved procedures. Physical damage to a cover or the pit support ledge is quite obvious, and damage which could compromise the effectiveness of a transfer system cover in performing its safety function is repaired before waste transfers are permitted to be routed through the pit.

2.18.8.4 Functional Requirements. The cover assembly for a pit or cleanout box must confine leaked waste to the inside of the structure. Covers must fit their supporting structures.

2.18.8.5 System Evaluation. Each time a cover is removed, the pit or box structure and cover shall be visually inspected for degradation in structural integrity. The exterior of the structure and cover assembly shall be visualiy inspected prior to a waste transfer to ensure that the following requirements are satisfied:

- Covers must be correctly installed.

- All cover plugs and seals must be correctly installed.

2.18.8.6 Supporting SSCs. None required. Transfer System Covers are passive SSCS.

\subsubsection{Service Water Flow Totalizers}

2.18.9.1 Safety $\mathrm{Classification.} \mathrm{The} \mathrm{Service} \mathrm{Water} \mathrm{Flow} \mathrm{Totalizers} \mathrm{are}$ identified as safety-significant SSCs for the Surface Leak Resulting in Pool accident.

\subsubsection{Safety Function(s). Monitor flow of service water.}

2.18.9.3 System Description. Service water flow totalizers provide total flow information that is used to track water usage in tank farms. A local reading is taken and compared with the previous reading to determine the amount of water used since the last reading. The amount is compared with expected usage. An unexpected increase in water usage may indicate a line leak or rupture, which could cause dilute waste to fill and overflow a waste storage tank or receiver tank. Service water flow totalizers are provided for tank farms 241-AN, 241-AP, 241-AW, 241-AX (two totalizers), 241-AY, 241-AZ, 241-BY, 241-C, and 241-SY, for 204-AR and 244-AR, and for DCRT 244-TX. The 
flow totalizer for DCRT 244-BX is inactive; the tank level detector must be used to detect service water intrusion into that tank. The remaining tank farm facilities do not have service water supplies, and totalizers are therefore not necessary to protect those facilities from service water intrusion.

2.18.9.4 Functional Requirements. The service water flow totalizers listed below shall provide local indication of water usage with an accuracy within \pm $5 \%$.

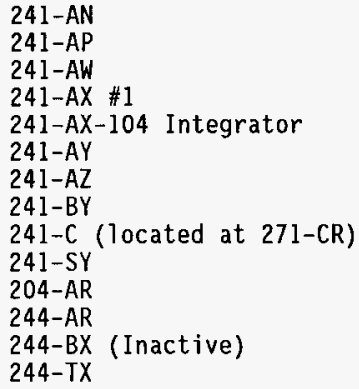

2.18.9.5 System Evaluation. The flow totalizer shall be calibrated annually.

2.18.9.6 Supporting SSCs. None.

\subsection{SUBSURFACE LEAK RESULTING IN POOL (19)}

\subsubsection{Pipe Encasements}

2.19.1.1 Safety Classification. The Pipe Encasements for the waste transfer system are identified as safety-class SSCS for the Subsurface Leak Resulting in Pool accident.

2.19.1.2 Safety Function(s). Ensure that a leak in the primary waste transfer system piping is directed to a waste transfer-associated structure.

2.19.1.3 System Description. Waste transfer system piping is encased by one of two methods:

- It is fabricated as pipe within a pipe, with an inner or primary pipe surrounded by an encasement or secondary pipe. The encasement pipe forms a sloped annular drain channel, and any leaked waste from a primary pipe will gravity flow from the leak site along this annular channel.

- The primary pipe(s) are confined in a concrete encasement. The concrete encasement forms a sloped drain channel, and any leaked waste from a primary pipe will gravity flow from the leak site along this channel.

Regardless of the encasement form, leaked waste will be channeled through the loop seals (with valves fully open), and into a transfer- 
associated structure along the transfer route, where the transfer leak detection system (described in Section 2.18.1) will detect the leaked waste.

Pipe encasements are vulnerable to damage during excavation activities in Tank Farms, particularly when powered equipment is used for digging.

2.19.1.4 Functional Requirements. The pipe encasement shall route waste leaked from the primary pipe to a structure where the leak can be detected. (The leak detection system is described in Section 2.18.1 of this document.) The encasement shall provide an unobstructed flow path to the structure.

2.19.1.5 System Evaluation. The drain path into the pit(s) from the annulus of the encased piping system shall be verified to be free of obstructions (i.e., the loop seal valves shall be in their fully open position) prior to the start of a waste transfer.

2.19.1.6 Supporting SSCs. None.

\subsubsection{Tank Level Detection Systems}

2.19.2.1 Safety Classification. The Tank Level Detection Systems are identified as safety-significant SSCs for the Subsurface Leak Resulting in Pool accident.

2.19.2.2 Safety Function(s). Provide tank waste level to support performance of periodic mass balances during waste transfers to detect waste leaks.

2.19.2.3 System Description. Each DST, SST, DCRT, and catch tank is equipped with a surface level detection system. Each system includes at least one level detector, which may be a manual tape, an FIC, an ENRAF gauge, or a set of dip tubes. Each DST has either an FIC or an ENRAF gauge and a manual tape backup; most SSTs, DCRTs, and catch tanks have a single level detector. Level data can be locally read, and are automatically or manually provided to TMACS and/or CASS. The 241-SY-101 level detection system contains both an FIC and an ENRAF gauge, and provides data to DACS as well as to TMACS. Level increases and decreases are detected by comparison of current level measurements with previous measurements. Mass balance discrepancies are detected by calculation using readings obtained at specified intervals during a waste transfer.

Five types of tank level detection systems are employed in Tank Farms. A dissatisfaction with the unreliability of the manual tapes and FIC level gauges led to their gradual replacement with the more reliable ENRAF gauges. An additional reason for switching to ENRAF gauges is that their electronic microprocessors can easily transmit additional and important level data to instrument buildings and to TMACS.

2.19.2.4 Functional Requirements. The level detection systems for all DSTs, including AWF tanks, and DCRTs shall provide level measurements prior to transfers to or from the tanks, and at specified intervals during the transfers, to support mass balance calculations.

The level detection systems for all DSTs, DCRTs, catch tanks, and SSTs that are not in intrusion prevention (interim isolation) status shall provide 
WHC-SD-WM-RD-057, Rev. 0

level measurements prior to waste transfers when the tanks are interconnected to the transfer route, and at specified intervals during the transfers, to detect misroutes.

The tank level detection systems shall measure waste levels with an accuracy of $\pm 1.3 \mathrm{~cm}$ ( $\pm 0.5 \mathrm{in.})$

2.19.2.5 System Evaluation. Tank level detection systems shall be calibrated annually to ensure compliance with the functional requirements stated above.

2.19.2.6 Supporting SSCs. Electrical power, instrument air, CASS, TMACS, DACS.

\subsubsection{Salt Well Flow Totalizers}

2.19.3.1 Safety Classification. The Salt Well Flow Totalizers are identified as safety-significant SSCs for the Subsurface Leak Resulting in Pool accident.

2.19.3.2 Safety Function(s). Provide total salt well flow to support performance of periodic mass balances during waste transfers to detect waste leaks.

2.19.3.3 System Description. The salt well skid flow totalizer is a nonintrusive device (a magnetic flow element) which measures the quantity of waste liquid transferred by the salt well pump. Each salt well pump system is provided with a flow totalizer.

Salt well flow totalizers have a good performance history in Tank Farms with a mean time between failures measured in years.

2.19.3.4 Functional Requirements. The flow totalizer instrument loop must be:

- Installed per manufacturers instructions

- Operated within the design limits of the instrumentation system

- Calibrated annually to within $\pm 5 \%$ of its full range.

2.19.3.5 System Evaluation. The salt well flow totalizer instrument loop must be calibrated annually to an accuracy of $\pm 5 \%$ of its full range. Instrument loop calibration must be done by trained personnel using approved procedures.

2.19.3.6 Supporting SSCs. Electrical power for the flow totalizer instrumentation loop.

\subsection{SPRAY LEAK IN STRUCTURE OR FROM OVERGROUND WASTE TRANSFER LINES (20)}

\subsubsection{Transfer System Covers}

2.20.1.1 Safety Classification. The Transfer System Covers are identified as safety-class SSCs for the Spray Leak in Structure or from Overground Waste Transfer Lines accident. 
2.20.1.2 Safety Function(s). Knockdown spray, limit release of aerosols to the atmosphere.

2.20.1.3 System Description. Permanent covers are typically heavy sections of reinforced concrete, although some covers are made from steel plate per their design documentation. Temporary covers are discouraged, but if used, must be fabricated according to released engineering documents and meet the functional requirements of permanent covers. Appendix $B$ of this document lists the waste transfer system covers that are safety-class SSCs during a waste transfer operation which includes the transfer associated structure on the active transfer route.

Concrete transfer system covers have demonstrated excellent durability in Tank Farm service, even though they are vulnerable to rough handling during removal and replacement. Appropriate lifting equipment is used to remove and replace covers, and all lifts are performed to approved procedures. Physical damage to a cover or the structure support ledge is quite obvious, and damage which could compromise the effectiveness of a transfer system cover in performing its safety function is repaired before waste transfers are permitted to be routed through the structure.

2.20.1.4 Functional Requirements. The cover assembly for a structure must confine spray leaks to the inside of the structure. Transfer system covers must el iminate direct spray leakage paths. Covers must fit their supporting structure.

2.20.1.5 System Evaluation. Each time a cover is removed, the pit structure and cover shall be visually inspected for degradation in structural integrity. The exterior of the pit and cover assembly shall be visually inspected prior to a waste transfer to ensure that the following requirements are satisfied:

- Covers must be correctly installed.

- All cover plugs and seals must be correctly installed.

2.20.1.6 Supporting SSCs. None required. Transfer System Covers are passive SSCs.

\subsubsection{Pressure Switch Interlocks or Alarms (Water Service Lines)}

2.20.2.1 Safety Classification. The Pressure Switch Interlocks or Alarms (Water Service Lines) are identified as safety-class SSCs for the Spray Leak in Structure or from Overground Waste Transfer Lines accident.

2.20.2.2 Safety Function(s). Prevent backflow of waste into the service water line and potential leaks in structures (e.g., service pits) without mitigative safety SSCs preventing direct release to the atmosphere (i.e., covers, leak detectors).

2.20.2.3 System Description. A pressure at, or above, the set point of the pressure switch results in a change in condition of a set of control contacts which are connected into the liquid waste transfer pump motor control circuitry. This results in the actuation of an alarm, or of an interlock to stop or prevent operation of the transfer pump. When the transfer system is being flushed the pressure of the raw water flush is above the pressure switch 
set point thus securing the transfer in the shut down condition. During water flushing operations the pressure switch is valved into the transfer piping system. During waste transfer operations the pressure switch is valved out of the transfer piping system.

Pressure switches in service water supply lines and their interlocks with waste transfer pumps are considered reliable, with mean time between failures estimated in years.

2.20.2.4 Functional Requirements. A pressure switch is required to actuate an alarm, or to actuate an interlock to prevent or stop the liquid waste transfer pump from running, when a high pressure is detected from the service water system.

2.20.2.5 System Evaluation. The pressure switch must be operated within the manufacturers' design limits. The pressure switch must be calibrated annually. The alarm function, and the interlock function where provided, must be tested annually.

2.20.2.6 Supporting SSCs. Electrical control power to the pressure switch/transfer pump motor control system.

\subsubsection{Ventilation CAM Interlock Systems}

2.20.3.1 Safety Classification. The Ventilation CAM Interlock Systems are identified as safety-class SSCs for the Spray Leak in Structure or from Overground Waste Transfer Lines accident.

2.20.3.2 Safety Function(s). Ensure exhaust fan is shut down should exhaust HEPA filters break through. Prevent unfiltered aerosol release to the atmosphere.

2.20.3.3 System Description. The CAMs and interlocks on the ventilation exhaust stacks for all DSTs, all AWF tanks, all actively ventilated SSTs, all DCRTs, and the 204-AR building are required to perform the above safety function. The following is a list of those stacks.

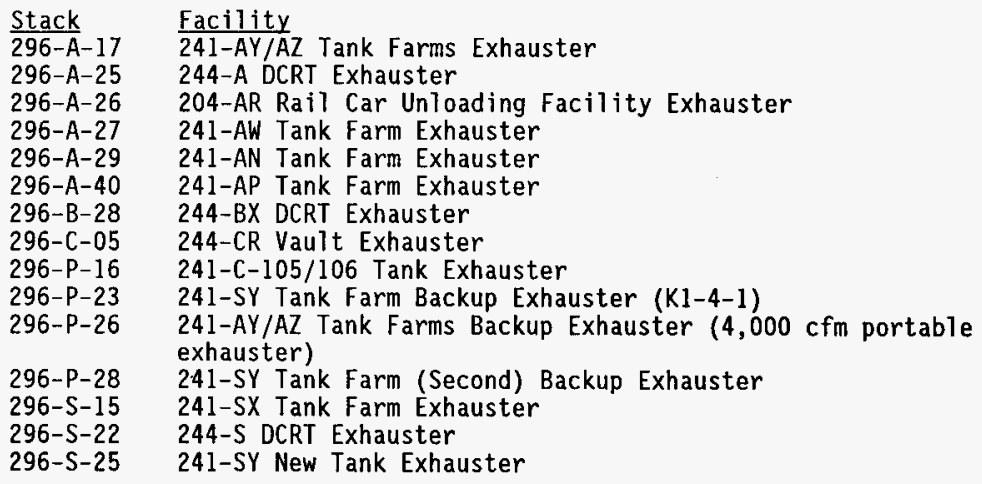




\section{6-T-18 244-TX DCRT Exhauster 296-U-11 244-U DCRT Exhauster}

Typically, a vacuum pump pulls a gaseous effluent sample from the exhaust stack through a sample line into the CAM, and discharges the sample either back to the stack or through a filter to the atmosphere. Isokinetic sampling conditions are maintained by automatic or manual adjustment of the flow rate. If the CAM detects high radiation in the exhaust stream, an alarm is actuated, and a signal is transmitted to a relay which interrupts the electrical power to the exhaust fan motor, causing the ventilation exhaust system to stop operating.

CAMs have not generally performed satisfactorily, with mean time between failures measured in months. The electrical interlock deenergizing the exhaust fan is considered reliable. CAMs are vulnerable to loss of sample flow; low sample flow rate and other CAM malfunctions are normally detected and alarmed.

2.20.3.4 Functional Requirements. The stack CAM must operate continuously while the exhaust systems are operating, and must be capable of alarming and shutting down the exhaust fan when radiation levels above background are detected in the stack.

2.20.3.5 System Evaluation. The CAMs shall be calibrated annually, and the alarms and interlocks shall be functionally tested once a month. The CAMs shall be source checked weekly to verify appropriate system response.

2.20.3.6 Supporting SSCs. Electrical power for the CAM, for the interlock and alarm, for the cabinet heaters and fans, and for freeze protection heaters for the gas tubing.

\subsubsection{OGT Encasement and Connections}

2.20.4.1 Safety Classification. The OGT Encasement and Connections are identified as safety-class SSCs for the Spray Leak in Structure or from overground Waste Transfer Lines accident.

2.20.4.2 Safety Function(s). Confine leak from the primary piping and ensure that a leak is directed to the encasement leak detection system.

2.20.4.3 System Description. OGT systems are temporary structures; they are designed, built, tested, used to transfer waste, flushed, and then disassembled. After disassembly, the OGT components are then either discarded as solid waste or stored for future use. The design of every OGT system is traceable to engineering design documents, which are kept current until the system is disassembled. Some of the components of an existing OGT system may be re-used in later OGT system assemblies, but this is not a requirement. OGT systems, because they are arrangements of temporary piping, are not listed in this discussion, and are described only in general terms.

The principal safety feature of an OGT system is the secondary encasement pipe assembly, which jackets and provides a confinement for the primary waste transfer pipe. If the inner OGT pipe develops a spray leak, the encasement of the OGT system will prevent the release of aerosolized waste to 
WHC-SD-WM-RD-057, Rev. 0

the atmosphere by confining the leaked waste, and safely routing it to a covered pit at the inlet or outlet end of the OGT system.

For corrosion resistance, the encasement sections are typically fabricated in short length flanged sections from 3 in. schedule 40 stainless stee 1 (304L) pipe. Typical encasement pipe sections include straight runs, 90,45 , and $22 \frac{1}{2}$ degree long-radius elbows, and other special bends as needed to construct the piping route.

Encasements for OGT lines have performed reliably whenever temporary OGT systems have been assembled and used.

2.20.4.4 Functional Requirements. The OGT Encasement and Connections system shall confine waste spray leaks from the primary pipe to the annulus between the encasement and the primary pipe, and shall divert the leaked waste to a pit at either end of the OGT Encasement and Connections system.

2.20.4.5 System Evaluation. Prior to a waste transfer, the integrity of an OGT encasement system must be confirmed by an pneumatic pressure test. The pneumatic test also confirms the integrity of the encased portions of the primary transfer line.

An OGT encasement system must be visually examined for damage or loss of integrity before a concrete shielding system section is set in place, and before waste transfer operations begin.

The position of the seal loop (encasement drain) valve at each end of the OGT transfer system must be verified before waste transfer operations can commence; at least one of the two seal loop valves, and preferably both, must be open. The seal loop drain hoses must be dressed to ensure that sufficient leaked waste can accumulate in the encasement drain path to reliably trigger the encasement leak detectors. Waste in the encasement drain hose will ultimately overflow the seal loop and drain to the pit floor for detection by the pit leak detectors.

\subsubsection{Supporting SSCs. None.}

\subsubsection{OGT Concrete Shielding System}

2.20.5.1 Safety Classification. The OGT Concrete Shielding System is identified as a safety-class SSC for the Spray Leak in Structure or from Overground Waste Transfer Lines accident.

2.20.5.2 Safety Function(s). Prevent vehicle collisions with the OGT system that could result in a loss of integrity of the primary and encasement pipe.

2.20.5.3 System Description. OGT systems are temporary structures; they are designed, built, tested, used to transfer waste, flushed, and then disassembled. After disassembly, the OGT components are either discarded as solid waste or stored for future use. The design of every OGT system is traceable to engineering design documents, which are kept current until the system is disassembled. Some of the components of an existing OGT system may be reused in later OGT system assemblies, but this is not a requirement. OGT systems, because they are arrangements of temporary piping and other 


$$
\text { WHC-SD-WM-RD-057, Rev. } 0
$$

supporting components, are not 1 isted in this discussion, and are described only in general terms.

Engineered steel-reinforced concrete radiation shields are emplaced over the assembled OGT encasement systems. The concrete shield section thickness varies according to the amount of radiation shielding required for the system. The concrete radiation shields protect the OGT system from vehicle impacts, which have the potential for causing spray release accidents of the type described in the accident analysis.

OGT concrete shielding systems are installed over assembled OGT transfer lines. The concrete shielding system components are susceptible to rough handling damage, e.g., by being dropped or by the impact of a heavy vehicle. Any structural damage is immediately obvious, however, and damaged components of the OGT concrete shielding system are either repaired before installation or discarded.

2.20.5.4 Functional Requirements. The OGT Concrete Shielding System installation shall conform to its engineering design documents. The system shall be capable of preventing damage to the OGT encasement and connections from vehicle impact.

2.20.5.5 System Evaluation. When the concrete shielding system sections are not installed over the OGT encasement system, access to the system by personnel and vehicles must be administratively controlled. An installed 0GT concrete shielding system must be visually examined for damage or loss of integrity before a waste transfer operation begins.

\subsubsection{Supporting SSCs. None.}

\subsubsection{4-AR Building}

2.20.6.1 Safety Classification. The 204-AR Building structure is identified as a safety-significant SSC for the Spray Leak in Structure or from Overground Waste Transfer Lines accident.

\subsubsection{Safety Function(s). Knockdown/confine spray within facility.}

2.20.6.3 System Description. The radiation zone of Building 204-AR has door pairs which form airlocks. The radiation zone of Building 204-AR has an exhaust system which contains a $30 \%$ filter and two HEPA filters in series. It also has a moisture separator in line and the exhaust to the stack is monitored by a CAM. Upon detection of radiation levels above background the CAM alarms and shuts down the exhaust fan.

The double entrance doors are the chief vulnerability of the 204-AR Building as a containment structure, since the doors must be opened to admit a railcar or tanker truck. The double entrance doors must be closed when waste transfer pumps are operating to ensure that airborne waste from a spray leak cannot escape from the building. Closing of the double entrance doors is an administrative control, and performance data on the effectiveness of this control is not available. 
WHC-SD-WM-RD-057, Rev. 0

2.20.6.4 Functional Requirements. Doors adjoining the radiation zone of 204$A R$, up to the second door, must remain closed at all times except when rail car passage is in progress.

2.20.6.5 System Evaluation. Prior to a waste transfer, all doors, up to the second door from the radiation zone, shall be verified closed.

2.20.6.6 Supporting SSCs. None.

\subsubsection{Backflow Prevention Devices}

2.20.7.1 Safety Classification. The Backflow Prevention Devices are identified as safety-significant SSCs for the Spray Leak in Structure or from overground Waste Transfer Lines accident.

2.20.7.2 Safety Function(s). Prevent contamination of the service water system via backflow of waste into service water line.

2.20.7.3 System Description. The reduced pressure backflow preventer is required by Washington State code to be installed in water 1 ines connecting to the site water distribution system when the connection is to radioactive or toxic materials. The backflow preventer is located outside the tank farm boundary at locations where raw water is supplied to the tank farms. The backflow preventer consists of two check valves to prevent backflow from the tank farms into the raw water system. Between the two check valves there is a reduced differential pressure relief valve which drains the interspace during a backflow condition. The backflow preventer is required to be approved by the state, and its installation must be inspected and tested by state certified personnel.

Backflow preventers have a long history of reliable performance, both in Tank Farms and offsite in public water supply applications. Backflow preventers are failsafe devices.

2.20.7.4 Functional Requirements. The reduced pressure backflow preventer is required to prevent the backflow of waste from the tank farms into the site water distribution systems.

2.20.7.5 System Evaluation. The backflow preventer must be installed and maintained within the design limits set by the device approval (i.e. maximum pressure and temperature range). The backflow preventer must be tested annually and accepted by a state certified inspector.

2.20.7.6 Supporting SSCs. None. The backflow preventers are self-contained.

\subsection{SPRAY LEAK FRON UNDERGROUND WASTE TRANSFER LINES (21)} accident.

No safety-class or safety-significant SSCs were identified for this

\subsection{TANK BUMP (22)}


WHC-SD-WM-RD-057, Rev. 0

\subsubsection{Temperature Monitoring Systems}

2.22.1.1 Safety Classification. The Temperature Monitoring Systems are identified as safety-significant SSCs for the Tank Bump accident.

2.22.1.2 Safety Function(s). Monitor tank waste temperature to provide operators with information on the existing temperatures in the waste so that necessary actions can be taken to prevent reaching temperatures at which tank bumps or steam release events could occur.

2.22.1.3 System Description. Temperature monitoring systems for the following tanks are designated as safety-significant systems: 241-C-106, 241SX-103, 241-SX-107, 241-SX-108, 241-SX-109, 241-SX-110, 241-SX-111, 241-SX$112,241-5 X-114$, a 11 DSTs, and a11 AWF tanks. Tank waste temperature monitoring systems include thermocouple trees and multi-function instrument trees (MITs). Waste temperatures can be read by the Temperature Monitoring and Control System (TMACS), field mounted panel monitors, or locally by hand held temperature monitoring instrumentation. The thermocouple tree is equipped with temperature detectors placed at $61.0 \mathrm{~cm}(2 \mathrm{ft})$ intervals within the tank (the distance of the lowest detector from the tank bottom varies from tank to tank). The MIT includes temperature detectors as well as vapor probe chambers for vapor sampling. The MIT contains 27 thermocouples evenly spaced at different heights, from the bottom of the tank up into the tank vapor space. The MIT output signals are transmitted automatically to TMACS.

The temperature monitoring system for waste tanks is considered reliable, as multiple thermocouples are installed in each tank. Failure of some of the thermocouples therefore does not prevent measurement of waste temperatures. Electrical power interruptions may interfere with data transmission to CASS or TMACS, but temperatures can always be read locally, if required, by means of calibrated millivoltmeters connected temporarily to the thermocouple wires.

2.22.1.4 Functional Requirements. The temperature monitoring systems shall be capable of detecting and displaying the temperature of tank waste over the full range of tank operations, including temperatures resulting from a loss of cooling event.

2.22.1.5 System Evaluation. The temperature monitoring systems shall be functionally tested annually to assure that each temperature display is within $\pm 5^{\circ} \mathrm{F}$ of the temperature read locally by a hand held temperature monitoring instrument at the thermocouple output signal connection.

2.22.1.6 Supporting SSCs. Electrical power for the transmitters and display systems. Electrical power is not required if a hand held battery operated temperature monitoring instrument is used.

\subsubsection{Tank Level Detection Systems}

2.22.2.1 Safety Classification. The Tank Level Detection Systems for DSTs and AWF tanks are identified as safety-significant SSCs for the Tank Bump accident. 
2.22.2.2 Safety Function(s). Monitor tank waste level to support implementing the tank temperature controls.

2.22.2.3 System Description. Each DST and AWF tank is equipped with a surface level detection system that includes either an FIC or an ENRAF gauge and a manual tape backup. (Exception: Tank 241-SY-101 has both an FIC and an ENRAF gauge as well as a manual tape.) Level data can be locally read, and are automatically or manually provided to TMACS and/or CASS.

Five types of tank level detection systems are employed in Tank Farms. A dissatisfaction with the unreliability of the manual tapes and FIC level gauges led to their gradual replacement with the more reliable ENRAF gauges. An additional reason for switching to ENRAF gauges is that their electronic microprocessors can easily transmit additional and important level data to instrument buildings and to TMACS.

2.22.2.4 Functional Requirements. The level detection systems for all DSTs and AWF tanks are required to measure tank waste levels above $4.6 \mathrm{~m}$ (15 feet) with an accuracy of $\pm 5.1 \mathrm{~cm}$ ( \pm 2 inches), and to transmit the data to local and/or remote level indicator.

2.22.2.5 System Evaluation. Tank level detection systems shall be calibrated annually to ensure compliance with the functional requirements stated above.

2.22.2.6 Supporting SSCs. Electrical power and instrument air for the level detection systems.

\subsection{NATURAL PHENOMENA (23)} accident.

No safety-class or safety-significant SSCs were identified for this 


\section{WHC-SD-WM-RD-057, Rev. 0}

\subsection{REFERENCES}

WHC-SD-WM-BI0-001, 1996, Tank Waste Remediation System Basis for Interim Operation, Revision 0 . Westinghouse Hanford Company, Richland, Washington.

LA-UR-92-3196, 1995, A Safety Assessment for Proposed Pump Mixing Operations to Mitigate Episodic Gas Releases in Tank 241-SY-101: Hanford Site, Richland, Washington, Revision 14. Los Alamos National Laboratory, Los Alamos, New Mexico.

WHC-SD-WM-JC0-007, 1996, Flammable Gas/S7urry Growth Unreviewed Safety Question: Justification for Continued Operation for the Tank Farms at the Hanford Site, Revision 0 . Westinghouse Hanford Company, Richland, Washington. 
WHC-SD-WM-RD-057, Rev. 0

This page intentionally left blank. 


\section{Appendix A. Accident/SSC Cross-Reference Table}

Table A-1 lists the safety SSCs discussed in Section 2.0 of this document. The table identifies, by number according to the following 1 ist, the accident(s) for which each SSC is identified as performing a safety function. The table also shows the safety classification of each SSC relative to each accident, using the code SS for safety-significant, and SC for safetyclass.

2 HEPA Filter Failure - Exposure to High Temperature or Pressure

7 Subsurface Leak Remaining Subsurface

10 Sodium Fire

12 Mixing of Incompatible Material - Tank Pressurization

14 Flammable Gas Deflagrations

18 Surface Leak Resulting in Pool

19 Subsurface Leak Resulting in Pool

20 Spray Leak in Structure or from Overground Waste Transfer Lines

22 Tank Bump 
WHC-SD-WM-RD-057, Rev. 0

This page intentionally left blank. 
WHC-SD-WM-RD-057, Rev. 0

Table A-1. Safety SSC/Accident Cross-Reference

\begin{tabular}{|c|c|c|c|c|c|c|c|c|c|}
\hline SSC Name & 2 & 7 & 10 & 12 & 14 & 18 & 19 & 20 & 22 \\
\hline 204-AR Building & & & & & & & & SS & \\
\hline 2727 W Building & & & SS & & & & & & \\
\hline Backflow Prevention Devices & & & & & & & & SS & \\
\hline DCRT Level Dip Tube Flow & & & & & SC & & & & \\
\hline DST/AWF Ventilation & & & & & SC & & & & \\
\hline $\begin{array}{l}\text { HEPA Filters (One stage required on } \\
244-S, 244-T X \text {, and } 244-A \text { ) }\end{array}$ & & & & SS & & & & & \\
\hline OGT Concrete Shielding System & & & & & & SC & & SC & \\
\hline OGT Encasement and Connections & & & & & & SC & & $\mathrm{SC}$ & \\
\hline Pipe Encasements & & SS & & & & & SC & & \\
\hline $\begin{array}{l}\text { Pressure Switch Interlocks or } \\
\text { Alarms (Water Service Lines) }\end{array}$ & & & & & & SC & & SC & \\
\hline Primary Tank Leak Detection Systems & & & & & SC & SC & & & \\
\hline Salt Well Flow Totalizers & & SS & & & & SS & SS & & \\
\hline Service Water Flow Totalizers & & & & & & SS & & & \\
\hline SST Ventilation & & & & & $S C$ & & & & \\
\hline SY-101 Ammonia Detection Systems & & & & & $\mathrm{SC}$ & & & & \\
\hline SY-101 Hydrogen Monitor & & & & & SC & & & & \\
\hline SY-101 Level Monitoring System & & & & & SC & & & & \\
\hline SY-101 Mixer Pump & & & & & $\mathrm{SC}$ & & & & \\
\hline SY-101 Pressure Monitoring System & & & & & $\mathrm{SC}$ & & & & \\
\hline $\begin{array}{l}\text { SY-101 Temperature Monitoring } \\
\text { System }\end{array}$ & & & & & SC & & & & \\
\hline SY-101 Ventilation Flowmeter & & & & & $\mathrm{SC}$ & & & & \\
\hline Tank Level Detection Systems & & SS & & & & SS & SS & & SS \\
\hline Temperature Monitoring Systems & & & & & & & & & SS \\
\hline TK-002 244-AR Level Dip Tube Flow & & & & & SC & & & & \\
\hline Transfer Leak Detection Systems & & SS & & & & SC & & & \\
\hline Transfer System Covers & & & & & & SS & & SC & \\
\hline Ventilation CAM Interlock Systems & SS & & & & & & & SC & \\
\hline
\end{tabular}


WHC-SD-WM-RD-057, Rev. 0

This page intentionally left blank. 
WHC-SD-WM-RD-057, Rev. 0

\section{Appendix B. Safety-Class/Safety-Significant Transfer System Covers}

The following pages list the transfer system covers that perform safety functions for accidents 18, Surface Leak Resulting in Pool, and 20, Spray Leak in Structure or from Overground Waste Transfer Lines. 
WHC-SD-WM-RD-057, Rev. 0

This page intentionally left blank. 


\section{EAST AREA PITS}

Aging Waste Central/Sluice Pump Pits

$\begin{array}{llll}241-A Y-01 A & 241-A Y-01 B & 241-A Y-01 C & 241-A Y-01 D \\ 241-A Y-01 E & 241-A Y-02 A & 241-A Y-02 B & 241-A Y-02 C \\ 241-A Y-02 D & 241-A Y-02 E & 241-A Z-01 A & 241-A Z-01 B \\ 241-A Z-01 C & 241-A Z-02 A & 241-A Z-02 B & 241-A Z-02 C\end{array}$

Aging Waste Annulus Pump Pits

24I-AY-01F 241-AY-02F 241-AZ-01F 241-AZ-02F

Aging Waste Leak Detection/Encasement Pits

241-AY-101A

241-AY-102A

241-AZ-102

DST Valve Pits

241-AW-A

241-AN-B

241-AW-B

DST Central/Feed Pump Pits

241-AN-01A

241-AN-03A

241-AN-05A

241-AN-07A

241-AW-02A

241-AW-03A

241-AW-05A

241-AP-01A

241-AP-02D

241-AP-04A

241-AP-06A

241-AP-08A

DST Annulus Pump Pits

241-AN-01B

$241-A N-05 B$

241-AW-02B

241-AW-06B

241-AP-04B

241-AP-08B
241-AY-101B (Encasement)

241-AZ-101

241-AZ-101/102 (Encasement)

241-AP

241-AN-A
241-AN-02A

241-AN-04A

241-AN-06A

241-AW-01A

241-AW-02E (242-A Feed Pump Pit)

241-AW-04A

241-AW-06A

241-AP-02A

(Grout Feed Pump Pit) 241-AP-03A

241-AP-05A

241-AP-07A
241-AN-03B

241-AN-07B

241-AW-04B

241-AP-02B

241-AP-06B
241-AN-04B

241-AW-01B

241-AW-05B

241-AP-03B

241-AP-07B 
DST Leak Detection Pits

$\begin{array}{llll}241-A N-01 C & 241-A N-02 C & 241-A N-03 C & 241-A N-04 C \\ 241-A N-05 C & 241-A N-06 C & 241-A N-07 C & 241-A W-01 C \\ 241-A W-02 C & 241-A W-03 C & 241-A W-04 C & 241-A W-05 C \\ 241-A W-06 C & 241-A P-03 C & 241-A P-05 C & \end{array}$

DST Flush Pits

241-AN 241-AW 241-AP

SST Valve Pits

241-C

241-AX-B

$241-A-B$

241-BY-111B Valve Box (Inactive)

241-AX-A

241-A-A

241-BY-111A Valve Box (Inactive)

241-BY-109 Valve Box, Line V305 (Inactive)

24l-BY-109 Valve Box, Line 812 (Inactive)

SST Central/STuice Pits

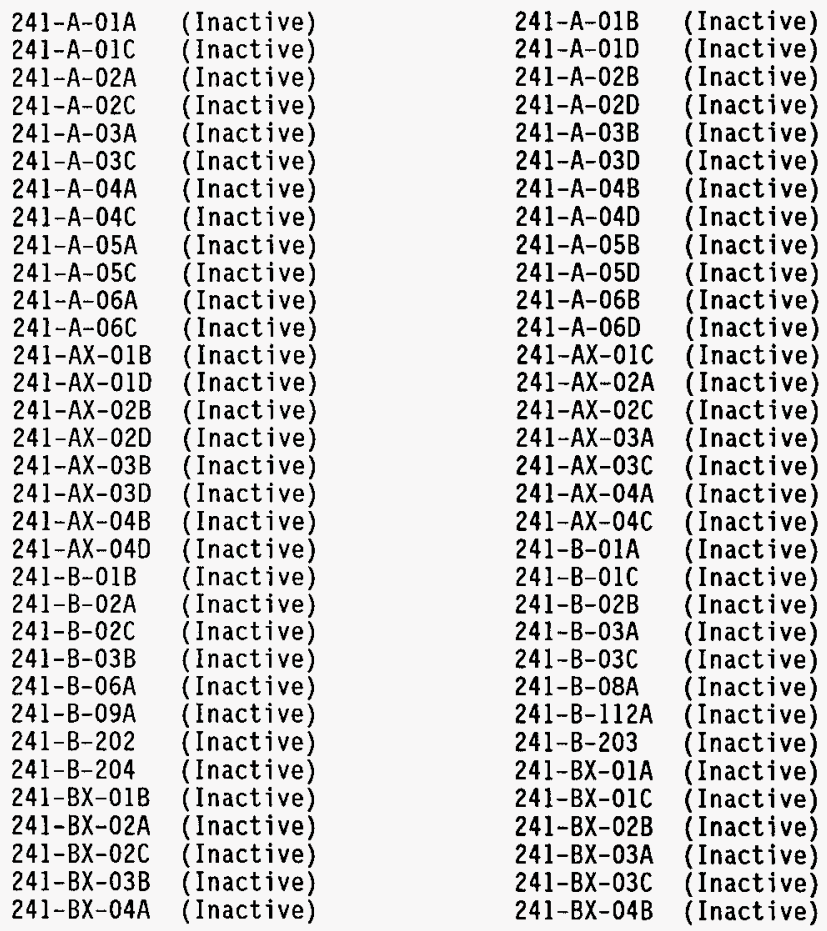




\begin{tabular}{|c|c|c|c|}
\hline $\begin{array}{l}241-B Y-02 A \\
241-B Y-02 C \\
241-B Y-03 A \\
241-B Y-03 D \\
241-B Y-04 C \\
241-B Y-05 A \\
241-B Y-05 D \\
241-B Y-06 C \\
241-B Y-07 A \\
241-B Y-09 A \\
241-B Y-111 A \\
241-B Y-111 D \\
241-B Y-112 C \\
241-C-01 A \\
241-C-01 C \\
241-C-02 B \\
241-C-03 A \\
241-C-03 C \\
241-C-04 B \\
241-C-05 A \\
241-C-05 C \\
241-C-06 B \\
241-C-201 \\
241-C-203 \\
241-A-01 H \\
241-A X-01 A \\
241-B-04 \\
241-B-05 \\
241-B-07 \\
241-B-110 \\
241-B-111 \\
241-B-201 \\
241-B X-07 \\
241-B X-09 \\
241-C-07 \\
241-C-08 \\
241-C-09 \\
241-C-110 \\
241-C-111 \\
241-C-112 \\
\text { a }\end{array}$ & $\begin{array}{l}\text { (Inactive) } \\
\text { (Inactive) } \\
\text { (Inactive) } \\
\text { (Inactive) } \\
\text { (Inactive) } \\
\text { (Inactive) } \\
\text { (Inactive) } \\
\text { (Inactive) } \\
\text { (Inactive) } \\
\text { (Inactive) } \\
\text { (Inactive) } \\
\text { (Slurry Distributor Pi } \\
\text { (Active for Salt Well } \\
\text { (No Pit; Covered Salt } \\
\text { (No Pit; Covered Salt } \\
\text { (No Pit; Covered Salt } \\
\text { (No Pit; Covered Salt } \\
\text { (No Pit; Covered Salt } \\
\text { (No Pit; Covered Salt } \\
\text { (No Pit; Covered Salt } \\
\text { (No Pit; Covered Salt } \\
\text { (No Pit; Covered Salt } \\
\text { (No Pit; Covered Salt } \\
\text { (No Pit; Covered Salt } \\
\text { (No Pit; Covered Salt } \\
\text { (No Pit; Covered Salt } \\
\text { (No Pit; Covered Salt }\end{array}$ & $\begin{array}{l}\text { 241-BX-05A } \\
241-B X-05 C \\
241-B X-06 B \\
241-B X-08 A \\
241-B X-111 A \\
241-B Y-01 A \\
241-B Y-01 D \\
241-B Y-02 B \\
241-B Y-02 D \\
241-B Y-03 C \\
241-B Y-04 A \\
241-B Y-04 D \\
241-B Y-05 C \\
241-B Y-06 A \\
241-B Y-06 D \\
241-B Y-08 A \\
241-B Y-110 A \\
241-B Y-111 C \\
241-B Y-112 A \\
241-B Y-112 D \\
241-C-01 B \\
241-C-02 A \\
241-C-02 C \\
241-C-03 B \\
241-C-04 A \\
241-C-04 C \\
241-C-05 B \\
241-C-06 A \\
241-C-06 C \\
241-C-202 \\
241-C-204 \\
\text { t; Active For } \\
\text { Pump } 1 \text { ing) } \\
\text { We11 Caisson, } \\
\text { We11 Caisson, } \\
\text { We11 Caisson, } \\
\text { We11 Caisson, } \\
\text { We11 Caisson, } \\
\text { We11 Caisson, } \\
\text { We11 Caisson, } \\
\text { We11 Caisson, } \\
\text { We11 Caisson, } \\
\text { We11 Caisson, } \\
\text { We11 Caisson, } \\
\text { We11 Caisson, } \\
\text { We11 Caisson, } \\
\text { We11 Caisson, }\end{array}$ & $\begin{array}{l}\text { Inactive) } \\
\text { Inact ive) } \\
\text { Inactive) } \\
\text { Inactive) } \\
\text { Inactive) } \\
\text { Inactive) } \\
\text { Inactive) } \\
\text { Inactive) } \\
\text { Inactive) } \\
\text { Inactive) } \\
\text { Inactive) } \\
\text { Inactive) } \\
\text { Inactive) } \\
\text { Inactive) }\end{array}$ \\
\hline
\end{tabular}

SST Leak Detection Pits

24I-AX-01E 241-AX-02E 241-AX-03E 241-AX-04E 
SST Flush Pits

241-A-A (Inactive)

241-A-B (Inactive)

241-AX-A (Inactive)

241-AX-B (Inactive)

Diversion Boxes

$\begin{array}{ll}241-A-151 & \\ 241-A-153 & \text { (Inactive) } \\ 241-A X-151 & \text { (Inactive) } \\ 241-A X-153 & \text { (Inactive) } \\ 241-A X-501 & \\ 241-A Y-152 & \text { (Inactive) } \\ 241-A Z-152 & \\ 241-B-152 & \text { (Inactive) } \\ 241-B-154 & \text { (Inactive) } \\ 242-B-151 & \text { (Inactive) } \\ 241-B X-153 & \text { (Inactive) } \\ 241-B X-155 & \text { (Inactive) } \\ 241-B X R-152 & \text { (Inactive) } \\ 241-B Y R-152 & \text { (Inactive) } \\ 241-B Y R-154 & \text { (Inactive) } \\ 241-C-152 & \text { (Inactive) } \\ 241-C-154 & \text { (Inactive) } \\ 241-C R-152 & \text { (Inactive) } \\ 241-E R-151 & \\ 241-E R-153 & \end{array}$

241-A-152 (Inactive)

241-AR-151

241-AX-152

241-AX-155

241-AY-151 (Inactive)

241-AY-501

241-B-151 (Inactive)

241-B-153 (Inactive)

241-B-252 (Inactive)

241-BR-152 (Inactive)

241-BX-154 (Inactive)

241-BXR-151 (Inactive)

241-BXR-153 (Inactive)

241-BYR-153 (Inactive)

241-C-151 (Inactive)

241-C-153 (Inactive)

241-CR-151 (Inactive)

241-CR-153 (Inactive)

241-ER-152

241-EW-151

Vault Pits

244-AR

244-BXR (Inactive)

Double-Contained Receiver Tank (DCRT) Pits

244-A Lift Station

244-BX

$244-C R$

Catch Tank Pits

$\begin{array}{llll}241-A-302 A & & 241-A-302 B & \text { (Inactive) } \\ 241-A-350 & & 241-A-417 & \\ 241-A X-152 & & 241-A Z-151 & \\ 241-A Z-154 & & 241-B-301 B & \text { (Inactive) } \\ 241-B-302 B & \text { (Inactive) } & 241-B X-302 A & \text { (Inactive) } \\ 241-B X-302 B & \text { (Inactive) } & 241-B X-302 C & \text { (Inactive) } \\ 241-301 C & \text { (Inactive) } & 241-E R-311 & \end{array}$


Cleanout Boxes

241-COB-AN-1

241-COB-AN-4

241-COB-AN-7

241-COB-AW-2

241-COB-AW-5

241-COB-AW-8

241-COB-AW-11

241-COB-AY-1

$241-C O B-A Z-3$

241-COB-AZ-6

241-COB-AZ-9
241-COB-AN-2

241-COB-AN-5

241-COB-AN-8

241-COB-AW-3

241-COB-AW-6

241-COB-AW-9

241-COB-AW-12

241-COB-AZ-1

241-COB-AZ-4

241-COB-AZ-7

241-COB-AZ-10
241-COB-AN-3

241-COB-AN-6

241-COB-AW-1

241-COB-AW-4

241-COB-AW-7

241-COB-AW-10

241-COB-A-30

241-COB-AZ-2

$241-\mathrm{COB}-\mathrm{AZ}-5$

$241-\mathrm{COB}-\mathrm{AZ}-8$

\section{WEST AREA PITS}

DST Valve Pits

$241-S Y-A$

241-SY-B

DST Central/Feed Pump Pits

241-SY-01A

24I-SY-02E (Inactive)

241-SY-02A

241-SY-03A

DST Annulus Pump Pits

241-SY-01B 241-SY-02B 241-SY-03B

DST Leak Detection Pits

241-SY-01C 241-SY-02C 241-SY-03C

DST Flush Pits

241-SY-A

241-SY-B (Inactive)

SST Valve Pits

241-S-A

241-S-B

241-S-C

241-S-D

241-SX-A

241-SX-B

241-TX-14B (Inactive)

241-TX-15B (Near 115-TX; Inactive)

241-UB

241-TX-15X (Near 115-TX; Inactive)

241-UD

241-UA

241-UC 
SST Central/Sluice Pits

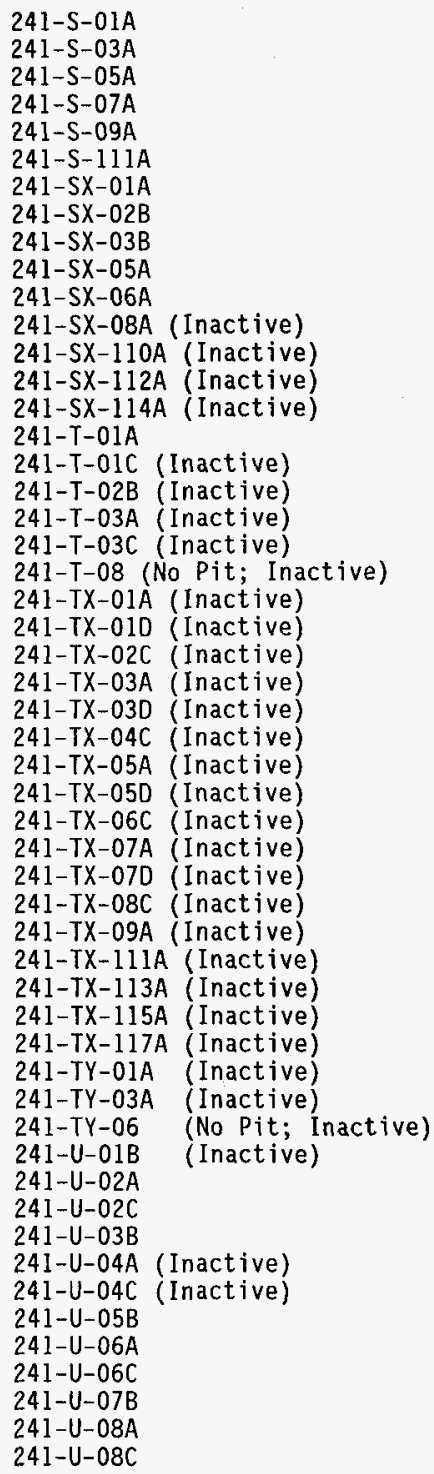

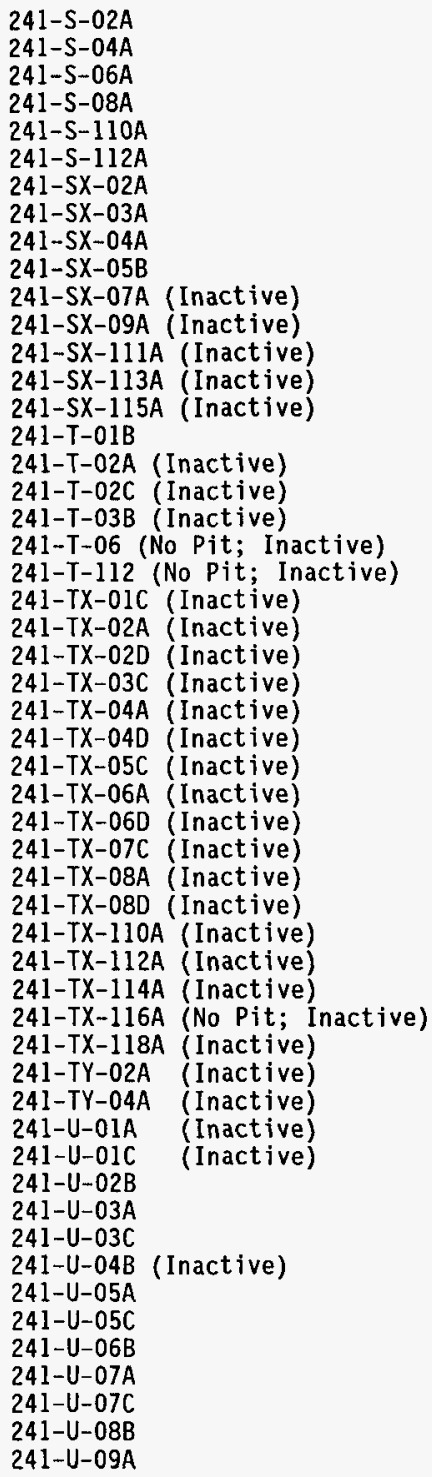


$241-U-09 B$

241-U-110A (Inactive)

241-U-111A

241-U-201 (Inactive)

241-U-203 (Inactive)

241-T-04 (No Pit; Covered Salt Well Caisson)

241-T-05 (No Pit; Covered Salt Well Caisson, Inactive)

241-T-07 (No Pit; Covered Salt Well Caisson)

241-T-09 (No Pit; Covered Salt Well Caisson)

241-T-110 (No Pit; Covered Salt Well Caisson)

241-T-111 (No Pit; Covered Salt Well Caisson)

241-T-201 (No Pit; Covered Salt Well Caisson, Inactive)

241-T-202 (No Pit; Covered Salt Well Caisson, Inactive)

241-T-203 (No Pit; Covered Salt Well Caisson, Inactive)

241-T-204 (No Pit; Covered Salt Well Caisson, Inactive)

241-TY-05 (No Pit; Covered Salt Well Caisson, Inactive)

241-U-112 (No Pit; Covered Salt Well Caisson, Inactive)

SST Flush Pits

241-S-A

241-UA

241-S-B

241-UB

Diversion Boxes
241-5X-A

241-UC
241-SX-B

241-UD

$\begin{array}{llll}240-S-151 & & 240-S-152 & \text { (Inactive) } \\ 241-S-151 & & 241-S-152 & \text { (Inactive) } \\ 241-T-151 & \text { (Inactive) } & 241-T-152 & \text { (Inactive) } \\ 241-T-153 & \text { (Inactive) } & 241-T-252 & \text { (Inactive) } \\ 241-T X-152 & & 241-T X-153 & \text { (Inactive) } \\ 241-T X-154 & & 241-T X-155 & \text { (Inactive) } \\ 241-T X R-151 & \text { (Inactive) } & 241-T X R-152 & \text { (Inactive) } \\ 241-T X R-153 & \text { (Inactive) } & 241-T R-152 & \text { (Inact ive) } \\ 241-T R-153 & \text { (Inactive) } & 241-T Y-153 & \text { (Inact ive) } \\ 241-U-151 & & 241-U-152 & \\ 241-U-153 & \text { (Inactive) } & 241-U-252 & \text { (Inactive) } \\ 241-U R-151 & \text { (Inactive) } & 241-U R-152 & \text { (Inactive) } \\ 241-U R-153 & \text { (Inactive) } & 241-U R-154 & \text { (Inactive) } \\ 241-U X-154 & & 241-W R & \text { (Inactive) } \\ 242-T-151 & \text { (Inactive) } & & \end{array}$

Vault Pits

24I-TXR-244 (Inactive) 241-UR-244 (Inactive)

Double-Contained Receiver Tank (DCRT) Pits

244-S 244-TX 244-U 
Catch Tank Pits

241-S-302 (Inactive)

241-S-304

241-T-301B (Inactive)

241-TX-302B (Inactive)

241-TY-302A (Inactive)

241-UX-302A

Cleanout Boxes

241-COB-SY-1

$241-C O B-S Y-4$

$$
\begin{array}{ll}
241-S-302 A & \text { (Inactive) } \\
241-S X-302 A & \text { (Inactive) } \\
241-T X-302 A & \text { (Inact ive) } \\
241-T X-302 C & \text { (Inact ive) } \\
241-T Y-302 B & \text { (Inactive) }
\end{array}
$$

241-COB-SY-2

241-COB-SY-5

241-COB-SY-3

241-COB-SY-6 


\section{DISTRIBUTION SHEET}

\begin{tabular}{|c|c|c|c|c|c|}
\hline \multirow{2}{*}{$\begin{array}{l}\text { To } \\
\text { Distribution }\end{array}$} & \multirow{2}{*}{\multicolumn{3}{|c|}{$\begin{array}{l}\text { From } \\
\text { Safety and Licensing }\end{array}$}} & \multicolumn{2}{|c|}{ Page 1 of 1} \\
\hline & & & & \multicolumn{2}{|c|}{$\begin{array}{l}\text { Date } \\
\text { September 30, } 1996\end{array}$} \\
\hline \multirow{2}{*}{\multicolumn{4}{|c|}{$\begin{array}{l}\text { Project Title/Work Order } \\
\text { BIO Project }\end{array}$}} & \multicolumn{2}{|c|}{ EDT No. 613528} \\
\hline & & & & \multicolumn{2}{|c|}{ ECN No. } \\
\hline Name & MSIN & $\begin{array}{c}\text { Text } \\
\text { With All } \\
\text { Attach. }\end{array}$ & Text Only & $\begin{array}{l}\text { Attach./ } \\
\text { Appendix } \\
\text { Only }\end{array}$ & $\begin{array}{l}\text { EDT/ECN } \\
\text { Only }\end{array}$ \\
\hline $\begin{array}{l}\text { J.R. Andrews } \\
\text { J.F. Bores } \\
\text { L.M. Calderon } \\
\text { R.A. Dodd } \\
\text { G.L. Dunford } \\
\text { S.L. Engstrom } \\
\text { L.A. Garner } \\
\text { J.E. Geary } \\
\text { D.F. Hicks } \\
\text { J.L. Homan } \\
\text { M.N. Islam } \\
\text { J.J. Klos } \\
\text { R.E. Lerch } \\
\text { G.A. Meyer } \\
\text { W.E. Miller } \\
\text { N.J. Milliken } \\
\text { R.S. Popielarczyk } \\
\text { J.G. Propson } \\
\text { R.D. Raaz } \\
\text { D.P. Reber } \\
\text { S.H. Rifaey } \\
\text { W.E. Ross } \\
\text { O.M. Serrano } \\
\text { P.L. Smith } \\
\text { M.A. Smith-Fewell } \\
\text { J.L. Stewart } \\
\text { A.R. Tedeschi } \\
\text { R.P. Tucker } \\
\text { J.E. Truax } \\
\text { A.M. Umek } \\
\text { M.D. VanderZanden } \\
\text { J. Weber } \\
\text { J.H. Wicks } \\
\text { J. Young } \\
\text { C. Zaccone } \\
\text { Central Files (Original + 3) }\end{array}$ & $\begin{array}{l}\text { S5-04 } \\
\text { S1-57 } \\
\text { R3-01 } \\
\text { S5-07 } \\
\text { A2-34 } \\
\text { R2-50 } \\
\text { R2-36 } \\
\text { S5-07 } \\
\text { A2-34 } \\
\text { H5-68 } \\
\text { R3-08 } \\
\text { R2-54 } \\
\text { S7-85 } \\
\text { S2-48 } \\
\text { R1-56 } \\
\text { A3-37 } \\
\text { A2-34 } \\
\text { R2-36 } \\
\text { R2-40 } \\
\text { T4-07 } \\
\text { R1-56 } \\
\text { S5-07 } \\
\text { R2-54 } \\
\text { R3-08 } \\
\text { H5-68 } \\
\text { A2-26 } \\
\text { R1-56 } \\
\text { A2-34 } \\
\text { R2-50 } \\
\text { S7-81 } \\
\text { H5-68 } \\
\text { B1-13 } \\
\text { R2-50 } \\
\text { A2-34 } \\
\text { A2-34 } \\
\text { A3-88 }\end{array}$ & 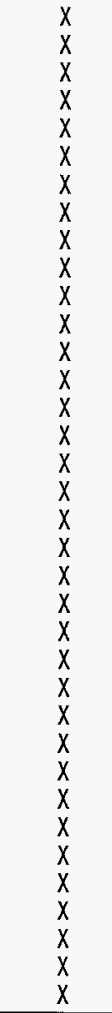 & & & \\
\hline
\end{tabular}

